\title{
Las campañas de vacunación contra la poliomielitis en Jerez de la Frontera (1963-1965)
}

Vaccination campaigns against polio in Jerez de la Frontera

(1963-1965)

\section{As campanhas de vacinação contra a poliomielite em Jerez de la Frontera (1963-1965)}

\author{
Francisco Herrera-Rodríguez \\ Catedrático de Escuela Universitaria. Facultad de Enfermería y Fisioterapia (Universidad de Cádiz) \\ "Trabajo realizado en el marco del proyecto HAR2012-39655-C04-03 del MINECO"
}

Cómo citar este artículo en edición digital: Herrera Rodríguez, F. (2015). Las campañas de vacunación contra la poliomielitis en Jerez de la Frontera (1963-1965). Cultura de los Cuidados (Edición digital), 19(43). Disponible en:< http://dx.doi. org/10.14198/cuid.2015.43.08>

Correspondencia:FranciscoHerrera-Rodríguez.FacultaddeEnfermeríayFisioterapia.Avda.AnadeViya,52.11009-Cádiz. Correo electrónico: francisco.herrera@uca.es

Recibido: 09/06/2015; Aceptado: 11/10/2015

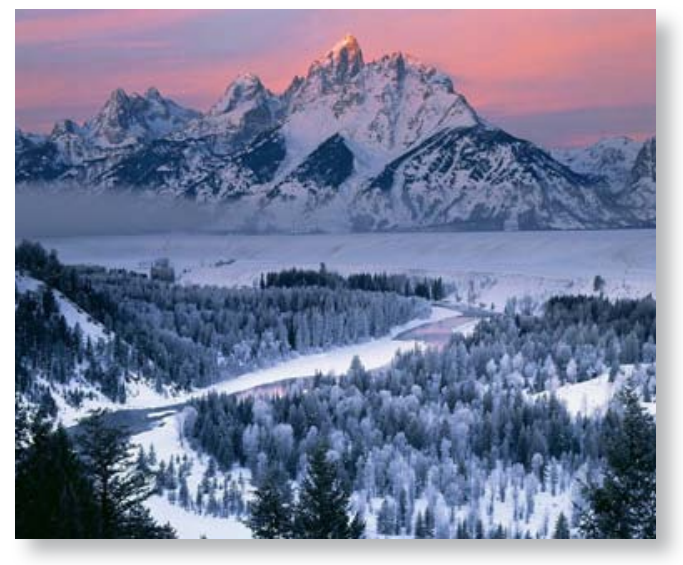

ABSTRACT

The aim of this article is to study the two phases of the poliomyelitis' vaccination campaign in the years 1963 and 1964, with the Sabin oral vaccine, in the city of Jerez de la Frontera (Cádiz). We also expound some data about the vaccination campaign in 1965 against polio, diphtheria, whooping cough and tetanus in the same city. We have used, in our study, original documents sources from Municipal Archives of Jerez, other archives and libraries of the province, as well as local, regional and national press, which have pro- vided us some information on the mentioned vaccination campaigns.

Key words: Polio Vaccination Campaign, Vaccination, Diphtheria, Pertussis, Whooping Cough, Tetanus, XX Century, Preventive Medicine, Sanitary Policy, Jerez de la Frontera, Cádiz, Spain.

\section{RESUMO}

Neste artigo temos que definir o objetivo de estudar as duas fases da campanha de vacinação contra a poliomielite em 1963 e 1964, com a vacina oral Sabin, na cidade de Jerez de la Frontera (Cádiz). Os dados também expor a campanha de vacinação contra a poliomielite em 1965, a difteria, coqueluche e tétano naquela cidade. Nós utilizado em nosso estudo fontes documentais originais Jerez Arquivos Municipais e outros arquivos e bibliotecas da província, bem como da imprensa local, regional e nacional, que nós fornecemos informações sobre as campanhas de vacinação que motivaram nossa pesquisa.

Palavras-chave: campanha de vacinação da Poliomielite, a vacinação, a difteria, co- 
queluche, tétano, Jerez de la Frontera, Cádiz, século XX, Medicina Preventiva, A política de Sáude, Jerez de la Frontera, Cádiz, Espanha.

\section{RESUMEN}

En el presente artículo nos hemos planteado como objetivo estudiar las dos fases de la campaña de vacunación contra la poliomielitis de los años 1963 y 1964, con la vacuna oral Sabin, en la ciudad de Jerez de la Frontera (Cádiz). Asimismo exponemos datos de la campaña de vacunación del año 1965 contra la poliomielitis, la difteria, la tos ferina y el tétanos en la referida ciudad. Hemos utilizado en nuestro estudio fuentes documentales originales del Archivo Municipal de Jerez y de otros archivos y bibliotecas de la provincia, así como prensa local, regional y nacional, que nos ofrecen información sobre las campañas de vacunación que han motivado nuestra investigación.

Palabras clave: Poliomielitis, Campaña de vacunación, Vacunación, Difteria, Tos ferina, Tétanos, Siglo XX, Medicina Preventiva, Política Sanitaria, Jerez de la Frontera, Cádiz, España.

A mis padres que en las fechas que estudia este trabajo se preocuparon de que no me faltara ninguna vacuna, tampoco la de la polio, la del terrón de azúcar.

\section{INTRODUCCIÓN}

El problema de la polioliomielitis en España ha concitado en los últimos años el interés de diversos investigadores, entre los que podemos citar a Águila Maturana (2000 y 2002), Muñoz Singi (2007); Tuells (2008), Rodríguez-Sánchez y Seco-Calvo (2009), Báguena Cervellera (2000 y 2009), Martínez Pérez (2009a y 2000b), Rodríguez-Sánchez (2010, 2012, 2013, 2014, 2015, etc.), Porras Gallo (2014), Porras Gallo et al. (2012 y 2013), Ba- llester y Porras (2009 y 2012), Nájera (2006 y 2013), Herrera (2006, 2011, 2012 y 2015), etc. Una atención especial se está dispensando en algunas de estas investigaciones a la lucha contra la enfermedad durante el franquismo, período sobre el que Ayarzagüena Sanz (2013) ha realizado una excelente síntesis del marco político, económico, social y cultural. Incluso el 2 de julio de 2013, el Ministerio de Sanidad, Servicios Sociales e Igualdad (con el título "Celebración del 50 aniversario de la instauración de las campañas de vacunación antipoliomielitis en España"), organizó un homenaje a la figura del médico e investigador Florencio Pérez Gallardo, figura crucial en la lucha contra la poliomielitis en los años cincuenta y sesenta. En este acto intervinieron Ferrán Martínez Navarro, Eduardo Fernández-Cruz Pérez, Luis Valenciano Clavel, Rafael Nájera Morrondo, Gloria Trallero Masso, Odorina Tello Anchuela, Francisco Salmerón García, Aurora Limia Sánchez y Jesús Pérez. En ese mismo año la Revista Española de Salud Pública publicó en sus páginas el trabajo clásico de Florencio Pérez Gallardo, Luis Valenciano Clavel y Jesús Gabriel y Galán: "Resultados de la campaña nacional de vacunación antipoliomielítica por vía oral en España (Estudio virológico y epidemiológico)"; estudio al que haremos alusión en este trabajo y también muy particularmente a la figura del médico de San Fernando (Cádiz), Florencio Pérez Gallardo (1917-2006) (Nájera, 2006a; Nájera, 2006b; Rey Calero, 2006; Domingo y Contreras, 2006).

No es de extrañar que la poliomielitis en la España de Franco preocupe a los investigadores, aunque evidentemente la enfermedad tiene una huella histórica que no podemos sintetizar en estas páginas. Ateniéndonos solo a España, a finales del siglo XIX y en las pri- 
meras décadas del siglo XX, debemos subrayar la excelente revisión realizada por Porras Gallo (2014). En la España franquista, pues, preocupó la morbilidad y la mortalidad que generaba esta enfermedad (figura 1), y desde la década de los cincuenta y de los sesenta toda la problemática de la vacunación, primero con la llamada vacuna Salk y posteriormente con la vacuna de Sabin. Aunque, como es sabido, uno de los puntos de debate que sostienen en la actualidad los investigadores es el de si las campañas de vacunación llegaron tardíamente o no a nuestro país, y por tanto se podrían haber reducido más tempranamente las cifras de morbilidad y de mortalidad por la poliomielitis, incluso a finales de los cincuenta el Jefe provincial de Sanidad de Cádiz planteó la escasa difusión en la provincia gaditana de la vacuna Salk (Aristoy-Santos, 1959).

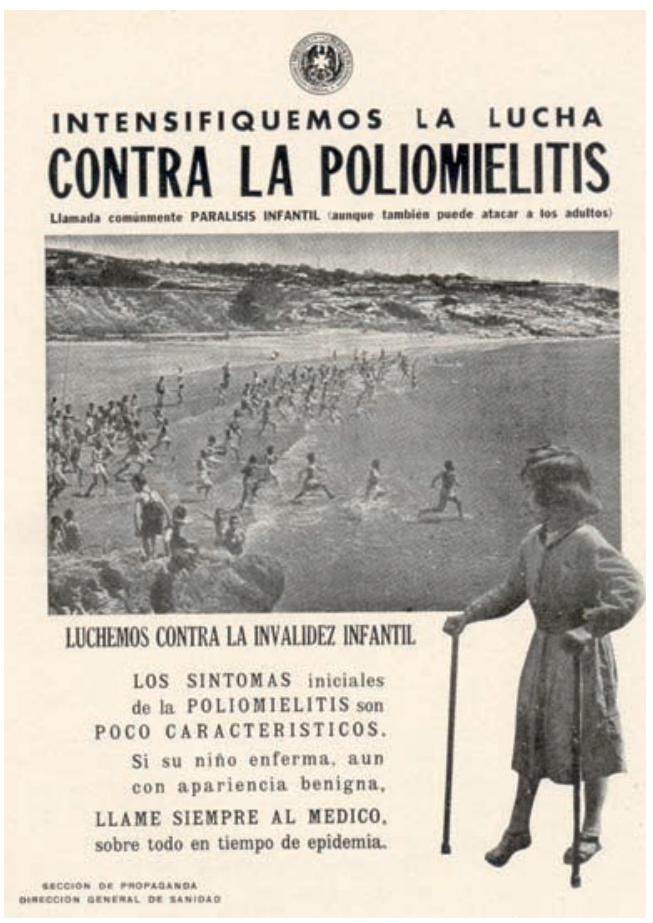

Figura 1: Cartel de la Dirección General de Sanidad para la lucha contra la poliomielitis. Fuente: González Rodríguez (1953).
El objetivo, pues, de nuestro trabajo es estudiar la organización de la campaña de vacunación contra la poliomielitis, con la vacuna oral Sabin, que se llevó a cabo en 1963 y 1964, en Jerez de la Frontera (Cádiz), en el contexto claro está de la campaña nacional; pero también nos proponemos comprobar si tuvo continuidad la vacunación contra la poliomielitis en Jerez en la siguiente campaña del año 1965.

Pero antes de exponer los resultados se impone que en esta introducción realicemos una breve reflexión sobre dos cuestiones concretas: en primer lugar una breve síntesis sobre la utilización de las vacunas de Salk y de Sabin contra la poliomielitis y en segundo lugar unos apuntes sobre la situación planteada por esta enfermedad en España y en la provincia de Cádiz en la década de los cincuenta y de los sesenta.

\section{Las vacunas de Salk y de Sabin}

En la historia de la investigación de la poliomielitis es de obligado cumplimiento resaltar la labor de muchos investigadores que desde la clínica o el laboratorio han contribuido a su mejor conocimiento y a paliar las graves secuelas que deja en las personas esta enfermedad (Herrera, 2011 y 2015). En este artículo tan solo recordaremos a Jonas Edward Salk (19141995) y Albert Bruce Sabin (1906-1993), investigadores que pusieron las bases para la lucha contra la poliomielitis con sus respectivas vacunas. El primero de ellos, Salk, a mediados de los años cincuenta aplicó la "vacuna inactiva$d a$ ", que se administraba intramuscularmente, mientras que la de Sabin era una "vacuna atenuada" que comenzó a suministrarse por vía oral a los niños con un terrón de azúcar a partir del año 1957. Sin los trabajos de estos investigadores no se podría haber puesto en marcha la vacunación masiva de la población. Aunque también se debe recordar que en EE.UU., entre 
1934 y 1935, Brodie y Kolmer, desarrollaron las primeras vacunas. Una contenía el virus inactivado y la otra el virus atenuado. Pero su administración produjo efectos adversos provocando casos graves de alergias, parálisis y muertes (León Rega y Echevarría, 2005). También cabe recordar los trabajos de Hilary Koprowski (1916-2013) que, junto con Jervis, planificó su ensayo en una residencia de niños con graves problemas mentales de Letchworth Village (Nájera, 2013b). No cabe duda de que la historia de la poliomielitis merece también una reflexión sobre el cumplimiento o no de los aspectos éticos en la experimentación en humanos.

Es importante apuntar que entre los años 1959 y 1963 se comenzó a utilizar la vacuna Salk en España, en niños que abarcaban la edad de cinco meses a los ocho años, concretamente en tres dosis, con un mes de intervalo, pero todo ello "con una baja cobertura de vacunación" (Pachón del Amo, 2004). Aunque también se debe precisar que la vacuna Salk estuvo disponible en España desde 1955, pero utilizándose de forma muy limitada en el ámbito de la medicina privada y no en campañas de vacunación propiciadas por las autoridades sanitarias "pese a la importante epidemia que sufría el país desde finales de los años 40". Se ha estimado que la decisión de combatir la epidemia de poliomielitis mediante campañas de vacunación promovidas y financiadas por los poderes públicos se tomó de forma muy tardía; si se hubiese utilizado activamente la vacuna de Salk desde el año 1956 "se hubieran evitado más de 12.000 casos de poliomielitis paralítica y más de 1.600 muertes por esta causa" (León Rega y Echevarria, 2005). También se ha apuntado el año 1957 como el de la introducción de la vacuna Salk: "La vacuna Salk introducida en 1957 se hace de forma individual, no asumi- da por la Seguridad Social y, aunque por una Orden del Ministerio de Trabajo (27.12.62) se ampliaba y se hacía gratuita, no tuvo ninguna influencia en la evolución de la enfermedad que, como ya hemos visto, desde 1957 a 1963, son los años de máxima incidencia" (Nájera, 2013a). Otros autores señalan que las campañas con Vacuna Salk se iniciaron en 1958 y que fueron llevadas a cabo por la Dirección General de Sanidad, fundamentalmente a través de las jefaturas provinciales $y$, si en éstas se consideraba oportuno, por los médicos titulares municipales (Rodríguez-Sánchez, 2010).

Nosotros hemos podido documentar vacunaciones con la vacuna Salk, en Cádiz capital, en los meses de febrero, marzo y abril de 1959, en la segunda mitad de 1960 y de 1961 a 1963, aunque no descartamos que se llegara a administrar en la provincia en 1958, sobre todo si tenemos en cuenta las palabras de Francisco Aristoy, jefe provincial de Sanidad, que transcribimos más adelante en este artículo. En 1961 se ofrece noticia en la prensa de una nota de la alcaldía de Cádiz en la cual se informa que en el primer semestre solo se había producido un caso de poliomielitis en la ciudad, mientras que en 1960 en el mismo periodo de tiempo se habían producido ocho casos, siempre en niños que no estaban vacunados. La alcaldía destaca la eficacia de la vacuna y se lamenta de que todavía existan en Cádiz padres que consideran peligrosa la vacunación (DC, 25-VI-1961). Llama la atención también que en algunas semanas de los meses de agosto y septiembre de 1963, en el municipio de Cadiz, no se administran las vacunas Salk contra la polio (aunque sí contra la difteria, la viruela y la fiebre tifoidea) por encontrarse la enfermera, "Julia", "enferma" o de "vacaciones". Y en lo que se refiere a la vacuna Sabin comprobamos que en Cádiz capital existen partes en los que 
consta que fue administrada a finales de 1963 y en 1964. Hay que apuntar que la información ofrecida la hemos obtenido de los partes emitidos por el Jefe local de Sanidad (Ayuntamiento de Cádiz) al Jefe provincial de Sanidad (Caja 3.831, AMC).

Centremos ahora nuestros comentarios en la vacuna de Sabin. En 1953, Sabin consiguió "las primeras cepas atenuadas útiles y en 1955 las administró a 80 voluntarios" (León y Echevarría, 2005). Entre 1954 y 1959 se administraron vacunas atenuadas a unas 350.000 personas (Singapur, Checoslovaquia, la URSS, los EE.UU., Holanda y Méjico). En 1959, la OMS asumió la coordinación de los estudios y en 1960 el comité de expertos en poliomielitis de esta institución emitió un informe en el que se recomendaba abiertamente el uso masivo de las vacunas atenuadas en los países que sufrían epidemias de poliomielitis y en los que la identificación de los grupos particularmente vulnerables no plantease ningún problema. Recuérdese, por ejemplo, que en ese mismo año fueron vacunadas 75 millones de personas con la vacuna Sabin en la URSS (León y Echevarría, 2005). Algunos autores señalan que Albert Bruce Sabin, entre 1961 y 1963, desarrolló las vacunas orales de la polio monovalente y trivalente (Fernández-Cruz y Rodríguez Sainz, 2013).

Es a partir de 1963, "siguiendo la experiencia de otros países", cuando se implantó en España la vacuna atenuada de Sabin, pero previamente a la primera campaña masiva de vacunación, se realizaron "una serie de estudios con el fin de conocer mejor el patrón epidemiológico de la enfermedad y poder adaptar la administración de la vacuna a nuestra situación real: estudio epidemiológico de los casos notificados de la poliomielitis; estudio de aislamiento de poliovirus en heces de niños sanos; y estudio serológico de detección de anticuerpos" (Pachón del Amo, 2004). Posteriormente, antes de la campaña nacional, se realizó una campaña piloto en las provincias de Lugo y León, a la que han dedicado un extenso y documentado estudio Rodríguez-Sánchez y Seco-Calvo (2009). Estos autores señalan que en el año 1963 se realizaron vacunaciones contra la polio con la vacuna Salk y con la vacuna oral de Sabin, circunstancia que también hemos podido comprobar en lo que se refiere al municipio de Cádiz (Cajas 3.831 y 3.834, AMC). La campaña con vacuna Salk fue puesta en marcha por el Seguro Obligatorio de Enfermedad (SOE) y la Dirección General de Sanidad promovió la experiencia piloto con vacuna oral Sabin. Según apuntan Rodríguez-Sánchez y Seco-Calvo, esto se planteó así por la pugna que sostenían ambos organismos por controlar la Medicina Preventiva en España. Motivo por el que la Dirección General de Sanidad anticipó su campaña de vacunación mediante "un ensayo de una novedosa vacuna trivalente oral en la provincia de León, aspectos que fueron ocultados a la población". La campaña piloto se llevó a cabo en las provincias de Lugo y León "en un clima de enfrentamiento entre los responsables nacionales y locales de la Dirección General de Sanidad y del Seguro Obligatorio de Enfermedad que saturaron la prensa de réplicas y contrarréplicas, convertidas en confuso mensaje para una población ajena al auténtico mensaje del debate". Asimismo los autores citados consideran que no fue un "ensayo meramente administrativo", debiéndose tener en cuenta que las vacunas fueron diferentes, "no sólo en los laboratorios, sino también en su composición: en tanto que León vacunaba en sus dos fases con vacuna trivalente (tipo I, II y III en la misma) y en dos grupos con diferentes concentraciones; en Lugo se vacunó en la primera 
fase con monovalente tipo I y en la segunda con bivalente II y III" (Rodríguez-Sánchez y Seco Calvo, 2009). Estos autores sostienen, pues, que la campaña piloto fue concebida como ensayo de la nueva vacuna trivalente y no como un mero ensayo administrativo. En cambio, Florencio Pérez Gallardo y cols., en su clásico artículo, reeditado en 2013, por la Revista Española de Salud Pública, señalaron que "para adquirir experiencia propia en el manejo de la vacuna y en la manera de llevar a cabo su distribución en las mejores condiciones, se efectuó en la primavera de 1963 una Campaña piloto de vacunación en las provincias de León y Lugo..." (Pérez Gallardo, Valenciano Clavel y Gabriel y Galán, 2013) (Pachón del Amo, 2004). José Tuells (2010), apoyándose en Nájera, Llácer y Valenciano (1975), ha señalado "el éxito de la campaña piloto contra la poliomielitis (19631964)". Y también ha sido calificada la campaña de 1963-1964 de "éxito indiscutible" (Nájera, 2013a). Controvertido tema que tan solo planteamos aquí, que será motivo con toda seguridad de nuevas investigaciones y debates en el futuro, remitimos en este aspecto a los trabajos que tiene en marcha Rodríguez Sánchez.

Aunque, en estas líneas introductorias, no podemos dejar de mencionar otras cuestiones que creemos tienen interés, recogidas del periódico ABC-M del día 2 de abril de 1958. Por ejemplo, el citado periódico dedica casi una página a la ayuda económica para la de investigación concedida a Florencio Pérez Gallardo (figura 2), por el Consejo del Patronato de la Fundación de Juan March. Pérez Gallardo en esos momentos era jefe de la Sección de Virus de la Escuela Nacional de Sanidad y estaba en posesión de un historial científico considerable ya que trabajó en el Instituto de Higiene de Varsovia y en los Laboratorios de la Fundación Rockefeller de Nueva York, además de haber descubierto, en colaboración con el doctor Cla- vero, la cepa E de Rickettsia prowazeki, y haber investigado sobre la fiebre "Q" y las vacunas contra la gripe y la rabia, sin olvidarnos de que era miembro de la Organización Mundial de la Salud. De todo esto da cuenta el periódico, pero también que la dotación económica ascendía a la cantidad de medio millón de pesetas y que el tema específico de la investigación que se debía desarrollar en el plazo de dos años era el siguiente: "Estudios de epidemiología y profilaxis de la poliomielitis en España. Desarrollo de las técnicas de aislamiento del virus y de preparación de vacunas en la parálisis infantil”. Sobre los estudios de seroprevalencia de Pérez Gallardo puede consultarse con provecho el trabajo de Ballester y Porras (2009).

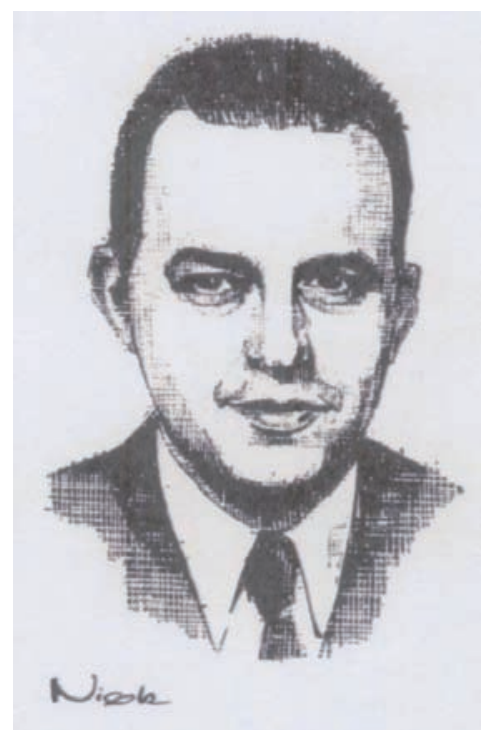

Figura 2: Florencio Pérez Gallardo (1917-2006). Fuente: Fundación Juan March. Ayudas de investigación (1957-1962).

El motivo por el que se concede esta ayuda se explica de la siguiente manera:

"Otra de las razones que justifican la concesión de la Ayuda de Investigación, es la situación que se ha creado en muchos países con motivo del descubrimiento, en los últimos años, de diversas vacunas contra la poliomielitis y su empleo masivo en unos casos (vacuna muer- 
ta tipo Salk) y en plano experimental en otros (vacunas vivas de los doctores Cox, Koprowski y Sabin). Resulta, pues, fundamental tener un conocimiento exacto de la situación epidemiológica de la poliomielitis en España, para lo que se necesita hacer un estudio serológico de la población (...). España debe prepararse con la debida cautela en el ritmo de adquisición de experiencia técnica para producir la vacuna antipoliomielítica que sea más conveniente. Así no dependeríamos de las regulaciones de exportación de los escasos países que la producen ni de las circunstancias comerciales".

Como se puede apreciar en los argumentos se utilizan factores científicos, pero también de tipo económico. El doctor Pérez Gallardo, pues, recibe esta ayuda para sus investigaciones en 1958, año especialmente duro en cuanto a la morbilidad y la mortalidad generada por la poliomielitis (véanse más adelante las tablas 1 y 2). Recuérdese que en el referido año se producen 2.079 casos de poliomielitis y 325 defunciones. Pero esta es una cuestión en la que profundizamos en el siguiente apartado de nuestra introducción. La ayuda económica a Pérez Gallardo, para las investigaciones sobre la poliomielitis, por parte de la Fundación Juan March, indican una preocupación latente de que el problema de esta enfermedad debía ser abordado de forma inminente porque la situación era acuciante. En 1953, la Asociación Europea contra la Poliomielitis señalaba "que sería prematuro formular una opinión sobre el valor y las posibilidades de la vacunación contra la poliomielitis en el estado actual de las investigaciones". Por este motivo "la Asociación recomienda que los países miembro deberían llevar a cabo, en los límites de sus recursos, ensayos científicos y bien controlados de estos métodos". En el V Simposio de esta Asociación (Madrid, 1958) se presentaron los informes de catorce países sobre el estado de vacunación, y no solo
España, también Francia, "estaban claramente rezagados, con bajos o prácticamente inexistentes niveles de vacunados" (Porras, Báguena, Ballester y de las Heras, 2012).

La poliomielitis en España y en la provincia de Cádiz en la década de los cincuenta y de los sesenta.

En España la situación se complicó en la década de los cincuenta, tan solo hay que repasar las cifras de morbilidad que presentó la enfermedad desde el año 1958 a 1962 (tablas 1 y 2).

\begin{tabular}{|c|c|}
\hline $\begin{array}{l}\text { ANOS } \\
(1950-1962)\end{array}$ & $\begin{array}{l}\text { MORBILIDAD } \\
\text { (Casos por } 100.000 \\
\text { habitantes) }\end{array}$ \\
\hline 1950 & 5,73 \\
\hline 1951 & 1,92 \\
\hline 1952 & 5,56 \\
\hline 1953 & 3,27 \\
\hline 1954 & 3,01 \\
\hline 1955 & 3,74 \\
\hline 1956 & 4,30 \\
\hline 1957 & 3,12 \\
\hline 1958 & 7,00 \\
\hline 1959 & 7,12 \\
\hline 1960 & 5,28 \\
\hline 1961 & 5,84 \\
\hline 1962 & 5,40 \\
\hline
\end{tabular}

Tabla 1. Poliomielitis. Tasas anuales de morbilidad por cien mil habitantes en España (1950-1962). Fuente: Cruz Hernández, 1972, tomo $2^{\circ}$, p. 1.555

Efectivamente, en España, como han señalado León y Echevarría (2005), "las epidemias más severas ocurrieron entre 1950 y 1963. Entre los años 1930 y 1950 se produjeron 400 casos anuales como media. Después esta cifra fue aumentando 
progresivamente hasta 1963, alcanzando los 1.500 casos anuales de media" (tabla 2).

\begin{tabular}{|c|c|c|}
\hline $\begin{array}{c}\text { ANOS } \\
(1949-1967)\end{array}$ & $\begin{array}{c}\text { NUMERO DE } \\
\text { CASOS }\end{array}$ & DEFUNCIONES \\
\hline 1949 & 522 & 104 \\
\hline 1950 & 1.597 & 127 \\
\hline 1951 & 541 & 118 \\
\hline$\overline{1952}$ & 1.576 & 165 \\
\hline 1953 & 935 & 121 \\
\hline 1954 & 867 & 117 \\
\hline 1955 & 1.085 & 117 \\
\hline 1956 & 1.258 & 158 \\
\hline 1957 & 919 & 151 \\
\hline 1958 & 2.079 & 325 \\
\hline 1959 & 2.130 & 328 \\
\hline 1960 & 1.632 & 208 \\
\hline 1961 & 1.778 & 218 \\
\hline 1962 & 1.853 & 192 \\
\hline 1963 & 1.959 & 210 \\
\hline 1964 & 193 & 43 \\
\hline 1965 & 70 & 34 \\
\hline 1966 & 308 & 37 \\
\hline 1967 & 362 & 34 \\
\hline
\end{tabular}

Tabla 2. Poliomielitis en España. Casos y defunciones (19491967). Fuente: Datos tomados de León y Echevarría (2005), que a su vez utilizan los de Nájera y cols. (1975).

Recuérdese, por ejemplo, que en el conjunto de la provincia de Cádiz, entre los años 1951 y 1953, fallecen por la poliomielitis aguda 21 personas, de las cuales 16 corresponden a hombres y 5 a mujeres. De estas 21 defunciones, 6 se producen en Cádiz capital (Reseña estadística de la provincia de Cádiz, 1957). En cuanto a la mortalidad, entre 1958 y 1975, la poliomielitis aguda en la provincia acaba con la vida de 123 personas (70 hombres y 53 mujeres), siendo especialmente duros en cuanto al número de defunciones los años 1958, 1959, 1960, 1962, 1963 y 1971 (tabla 3). Y en lo que se refiere a los casos presentados en la provincia de Cádiz, entre 1957 y 1971, tan solo hay que revisar la tabla 4 para comprender la situación que comentamos.

\begin{tabular}{|c|c|c|c|}
\hline $\begin{array}{c}\text { AÑos } \\
\text { (1958-1975) }\end{array}$ & $\begin{array}{c}\text { NÚMERO DE } \\
\text { DEFUNCIONES } \\
\text { POR } \\
\text { POLIOMIELITIS } \\
\text { AGUDA EN LA } \\
\text { PROVINCIA DE } \\
\text { CÁDIZ } \\
\text { (HOMBRES) } \\
\text { (1958-1975) } \\
\end{array}$ & $\begin{array}{c}\text { NÚMERO DE } \\
\text { DEFUNCIONES } \\
\text { POR } \\
\text { POLIOMIELITIS } \\
\text { AGUDA EN LA } \\
\text { PROVINCIA DE } \\
\text { CÁDIZ } \\
\text { (MUJERES) } \\
\text { (1958-1975) }\end{array}$ & $\begin{array}{c}\text { TOTAL DE } \\
\text { DEFUNCIONES } \\
\text { POR } \\
\text { POLIOMIELITIS } \\
\text { AGUDA EN LA } \\
\text { PROVINCIA DE } \\
\text { CÁDIZ } \\
(1958-1975)\end{array}$ \\
\hline 1958 & 18 & 9 & 27 \\
\hline 1959 & 5 & 4 & 9 \\
\hline 1960 & 22 & 16 & 38 \\
\hline 1961 & 4 & 1 & 5 \\
\hline 1962 & 8 & 6 & 14 \\
\hline 1963 & 5 & 5 & 10 \\
\hline 1964 & 1 & 1 & 2 \\
\hline 1965 & 0 & 2 & 2 \\
\hline 1966 & 2 & 1 & 3 \\
\hline 1967 & 0 & 1 & 1 \\
\hline 1968 & 2 & 0 & 2 \\
\hline 1969 & 0 & 1 & 1 \\
\hline 1970 & 0 & 0 & 0 \\
\hline 1971 & 2 & 5 & 7 \\
\hline 1972 & 0 & 0 & 0 \\
\hline 1973 & 0 & 0 & 0 \\
\hline 1974 & 0 & 0 & 0 \\
\hline 1975 & 1 & 1 & 2 \\
\hline TOTAL & 70 & 53 & 123 \\
\hline
\end{tabular}

Tabla 3: Defunciones en la provincia de Cádiz por poliomielitis aguda (hombres, mujeres y total) (1958-1975). Elaboración propia, 2015. Fuente: INE: Libros del Movimiento Natural de la Población de España (1958-1975).

\begin{tabular}{|c|c|}
\hline $\begin{array}{c}\text { PROVINCIA } \\
\text { DE CÁDIZ } \\
\text { (1957-1971) }\end{array}$ & $\begin{array}{c}\text { MORBILIDAD } \\
\text { (Casos por } \\
\mathbf{1 0 0 . 0 0 0} \\
\text { habitantes) }\end{array}$ \\
\hline $\mathbf{1 9 5 7}$ & 13,43 \\
\hline $\mathbf{1 9 5 8}$ & 26,21 \\
\hline $\mathbf{1 9 5 9}$ & 8,15 \\
\hline $\mathbf{1 9 6 0}$ & 35,2 \\
\hline $\mathbf{1 9 6 1}$ & 6,50 \\
\hline $\mathbf{1 9 6 2}$ & 14,46 \\
\hline $\mathbf{1 9 6 3}$ & 11,90 \\
\hline $\mathbf{1 9 6 4}$ & 0,23 \\
\hline $\mathbf{1 9 6 5}$ & 0,22 \\
\hline $\mathbf{1 9 6 6}$ & 3,40 \\
\hline $\mathbf{1 9 6 7}$ & 0,77 \\
\hline $\mathbf{1 9 6 8}$ & 0,76 \\
\hline $\mathbf{1 9 6 9}$ & 2,97 \\
\hline $\mathbf{1 9 7 0}$ & 1,25 \\
\hline $\mathbf{1 9 7 1}$ & 3,72 \\
\hline & \\
\hline & \\
\hline & \\
\hline
\end{tabular}

Tabla 4: Poliomielitis. Tasas anuales de morbilidad por cien mil habitantes en la provincia de Cádiz (1957-1971). Fuente: Revista de Sanidad e Higiene Pública. Elaborada y cedida para este trabajo por Juan Antonio Rodríguez Sánchez. 
En cambio, el periódico ABC en 1958 considera que la situación en torno a esta enfermedad no es preocupante en España, cierto es que cuando esto se escribe es en el mes de abril y quedan muchos meses para que concluya el año, pero hay que tener en cuenta que las cifras de 1957 eran también muy preocupantes: 919 casos y 151 defunciones (tabla 2) y en lo que se refiere a la provincia de Cádiz, en el año 1958, la poliomielitis se cobra la vida de 27 personas (tabla 3) y presenta una tasa de morbilidad de 26,21 casos por cien mil habitantes (tabla 4). Por eso merece la pena rescatar el siguiente párrafo del periódico, con el cual parece que se quita importancia a lo que está sucediendo (ABC-M, 2-IV-1958):

"El problema de la poliomielitis en España es actualmente de reducida intensidad. Sin embargo, hay que contar con que la endemia adquiera con el tiempo una mayor importancia, ya que, por excepción, esta infección aumenta al mejorar las condiciones de vida".

El mismo periódico, en enero de 1959, con motivo de un extenso artículo titulado "La sanidad de España ante la V Reunión Nacional de Sanitarios", reconoce la gravedad de la situación con respecto a la poliomielitis en nuestro país (ABC-M, 23-I-1959):

"La poliomielitis ofrece estas novedades: hasta fines de noviembre de 1958 el número de casos declarados oficialmente ha sido de 1.857. Extendida por todo el país no respetó ninguna provincia. La cifra es mayor que la calculada como promedio anual en el último decenio y es también superior a la más alta registrada en cualquiera de los años del mismo (...). Las provincias más afectadas han sido las de Cádiz, Sevilla y Lugo. Sin embargo, la cifra sigue sin constituir un problema de la importancia que ha adquirido en los Estados Unidos e Inglaterra, por ejemplo".
En el referido artículo también se hace mención de las dificultades existentes para obtener la vacuna, "toda de importación", motivo por el que la Escuela Nacional de Sanidad trabaja en la investigación para disponer de la vacuna antipoliomielítica en España; sin duda, en esta nota de prensa, se están refiriendo a las investigaciones lideradas por Florencio Pérez Gallardo, que como hemos visto fueron dotadas con medio millón de pesetas por la Fundación Juan March.

Pero de todo lo referido nos quedamos con un dato; en el año 1958, la provincia de Cádiz, junto con las de Sevilla y Lugo, es señalada como una de las más afectadas por la poliomielitis. Esta cuestión merece algunos comentarios fraguados desde una perspectiva local.

La situación en la provincia de Cádiz era complicada (tablas 3 y 4), y así lo manifestó Francisco Aristoy Santos, jefe provincial de Sanidad en Cádiz y profesor de Microbiología en la Facultad de Medicina, en la comunicación que presentó en 1958 en la V Reunión Nacional de Sanitarios que se celebró en Madrid. Nada menos que 878 casos de poliomielitis se registraron durante una década en el Instituto de Sanidad de Cádiz, apuntando también que se debe tener en cuenta que la campaña de vacunación estuvo "limitada a las poblaciones afectadas en las que se mantiene la endemia que son las situadas alrededor de las bahías de Cádiz y Algeciras" (Aristoy-Santos, 1959). Aristoy incluso se lamenta sobre la campaña de vacunación en la provincia gaditana de la siguiente manera:

"El ideal hubiera sido hacer una vacunación gratuita, en gran escala, en esta zona en que la Polio es endemoepidémica, y principalmente entre las clases de más débil economía, que son las más afectadas por la enfermedad, pero no dispusimos de ninguna subvención, si bien la 
Dirección General de Sanidad, preocupada por el problema, envió 130 dosis gratuitas para vacunar a los niños de la Línea de la Concepción".

Y prosigue Aristoy con algunos datos que subrayan aún más lo exigua que fue la vacunación en la provincia gaditana a finales de los años cincuenta:

"Además de la vacunación practicada en nuestros servicios del Instituto con la vacuna enviada por la Dirección General de Sanidad, al precio de 200 pesetas las tres dosis, algunos Ayuntamientos, la Diputación y varias entidades industriales la han llevado a efecto con carácter gratuito en determinados establecimientos benéficos y entre los hijos de sus empleados. Podemos calcular que, entre las controladas por nosotros y las practicadas libremente, suman un total de 6.295 vacunaciones".

Francisco Aristoy expuso con mucha claridad como estaba la situación en la provincia gaditana a finales de los años cincuenta y el panorama como hemos podido ver era de preocupación, y en cierta manera también el epidemiólogo manifestaba su impotencia ante la escasez de recursos y medios para combatir a la poliomielitis. Aristoy se mantuvo en su puesto de Jefe provincial de Sanidad de Cádiz hasta mayo de 1963 en que como apunta Diario de Cádiz, por jubilación, entregó su cargo a José Manuel Pérez Álvarez (DC 9 y 19-V1963).

\section{LA ORGANIZACIÓN DE LAS CAMPAÑAS DE VACUNACIÓN CONTRA LA POLIO EN JEREZ DE LA FRONTERA (1963-1964 y 1965)}

En 1963 se implantó en España la vacunación contra la poliomielitis con la vacuna atenuada de Sabin (VPO). La campaña fue gratuita y se centró en la vacunación de niños de dos meses a siete años. Como es sabido la campaña se desarrolló en dos fases, administrándose dos dosis de vacuna (Pachón del Amo, 2004):

“...en la primera fase (finales de 1963) con vacuna VPO monovalente de poliovirus 1 ( $m V P O)$ y la segunda (principios de 1964) con vacuna VPO trivalente de poliovirus 1, 2 y 3 (tVPO), alcanzándose una cobertura del 95\% en la primera fase y del $98 \%$ en la segunda, lo que provoca un descenso brusco de la incidencia de la enfermedad desde una media de 1.900 casos notificados en el periodo prevacunal a 195 casos en 1964".

En la primera fase de la campaña nacional se empleó, como hemos indicado, virus polio tipo 1 y fueron vacunados 4.400 .000 niños, es decir el 95\% de la población de entre dos meses y siete años. En la segunda fase la vacuna fue trivalente con los tipos 1,2 y 3 y cubrió a 4.680.000 niños, lo que representó el 98,8\% (Pérez Gallardo, Valenciano y Gabriel y Galán, 2013).

En lo que se refiere al Boletín Oficial de la Provincia de Cádiz, en los números de 9 de enero y 19 de febrero de 1963, se encuentran normativas reguladoras de la campaña de vacunación antipoliomelítica masiva durante los meses de enero a junio de 1963, en las que se puede comprobar la dicotomía existente en la vacunación (vacuna Salk) entre el Seguro Obligatorio de Enfermedad y la Dirección General de Sanidad, aspecto en el que no profundizamos porque ya lo han hecho otros autores (Rodríguez-Sánchez y Seco Calvo, 2009). En cambio nos sorprende que el Boletín Oficial de la Provincia de Cádiz no recoja normativas explícitas en lo referido a la campaña nacional de vacunación con la vacuna Sabin, que se llevó a cabo en dos fases a finales de 1963 y principios de 1964, más adelante concretaremos estas fechas.

Hemos podido comprobar, como ya hemos comentado, en lo que se refiere a Cádiz capital, que desde enero de 1963, en los partes de va- 
cunación semanales emitidos por el Jefe local de Sanidad (Ayuntamiento de Cádiz) al Jefe provincial de Sanidad, se hace constar durante todo el año vacunación contra la poliomielitis, con la vacuna inactivada de Salk (VPI), hasta el 23 de noviembre en que ya no constan vacunaciones contra la poliomielitis; aunque en las semanas del 7 al 14 y del 15 al 21 de diciembre constan en esos partes 120 vacunaciones por vía oral. Datos que consideramos incompletos y que evidentemente no reflejan la totalidad de las vacunaciones llevadas a cabo en Cádiz capital porque probablemente se consignarían los registros de vacunación en otros documentos que no hemos podido localizar (Caja 3.831, AMC). Aunque no es el objetivo de nuestro trabajo estudiar los pormenores de la Campaña de vacunación antipolio en Cádiz capital, podemos apuntar que la Jefatura provincial de Sanidad puso en marcha la segunda fase de la Campaña el lunes 30 de marzo de 1964, el mismo día que en Jerez de la Frontera, y que en la capital de la provincia se establecieron los siguientes Centros de vacunación, información que hemos recogido en el Archivo Municipal de Jerez de la Frontera (Legajo 1.929, expediente 36.654, AMJ):

- Escuela Padre Villoslada (Carretera Industrial).

- Guardería Infantil de Puertas de Tierra.

- Guardería de Nuestra Señora de Sonsoles (calle Brasil).

- Casa de Socorro de los Caballeros Hospitalarios (calle Benjumeda).

- Escuela Barriada de Puntales.

- Jefatura provincial de Sanidad (Olivillo).

- Casa de Socorro (Plaza de Toros).

- Colegio de la Viña (lugar en que la vacunación se hará el día 31).

Centrémonos ya en Jerez de la Frontera, importante localidad de la provincia de Cádiz, que en 1960 superaba los 130.000 habitantes (Capel Sáez, 1971; Caro Cancela, 1999). En 1963 las superficies de viñedos eran 2.518 hectáreas (Cabral Chamorro, 1990). Este dato nos puede llevar a deducir que la situación en la ciudad, en su conjunto, era próspera y boyante, pero había núcleos de población sumidos en la pobreza. La localización de un expediente con documentación de la Junta Municipal de Beneficencia de 1962-1963, refiere que en este último año se incluye en la "pobreza legal", y por tanto con derecho a la "asistencia médico-farmacéutica gratuita”, a 3.513 familias, sumando un total de 9.062 beneficiarios (Legajo 1.929, Expediente 36.653, AMJ). Es cierto que el período 1950-1985 ha sido el de mayor prosperidad para los vinos de Jerez; pero también hay que recordar la huelga de los viticultores de abril de 1962, reivindicando mejoras salariales, y la de 1964 que se prolongó casi dos meses. En los años sesenta muchos trabajadores españoles tuvieron que emigrar, también jerezanos, a diferentes países de Europa y a otras regiones de España; no olvidemos tampoco que Jerez se ha caracterizado por un reparto muy desigual de las riquezas (Ruiz Mata, 2010). Entre 1963 y 1965, años que abarca nuestro estudio, encontramos que se suceden dos alcaldes en la ciudad: Tomás García Figueras, hombre leal al Régimen y militar especialista en temas norteafricanos, y Miguel Primo de Rivera, sobrino del fundador de Falange. En esos años Jerez tenía problemas con las viviendas, la inmigración interior desde los núcleos rurales cercanos y la escolarización de los niños, tanto es así que Primo de Rivera reconoce que la falta de vivienda y de plazas escolares son dos gravísimos problemas que entorpecen el despegue de Jerez. El problema de la vivienda era acuciante por el estado insalubre y antihigiénico de los pisos del casco histórico, llegando la situación al "hacinamiento, el suburbio y el chabolismo a 
niveles alarmantes". Y no menos grave era el problema educativo, con cerca de 8.000 niños que no recibían enseñanza primaria por falta de escuelas (Caro Cancela, 1999).

Este es, pues, el contexto general en que se va a llevar a cabo en Jerez de la Frontera la campaña de vacunación que es motivo de nuestro estudio. Una campaña que como hemos dicho tuvo dos fases; concretamente, en Jerez, la primera fase abarcó del 25 de noviembre al 3 de diciembre de 1963, y la segunda fase del 30 de marzo al 8 de abril de 1864 (Legajo 1.929, Expediente 36.654, AMJ). Avisamos de que en la portada del citado expediente existe un error en las fechas de la segunda fase de la campaña; error, que se corrige estudiando la documentación que contiene. Precisamente esta documentación del archivo jerezano nos permite plantear cómo se organizó en la ciudad la campaña con la vacuna oral de Sabin en las dos fases que hemos indicado.

\subsection{La primera fase de la vacunación ( 25 de noviembre al 3 de diciembre de 1963)}

El 15 de noviembre de 1963, el Gobernador Civil de la provincia de Cádiz, Santiago Guillén Moreno, le remite una carta al Alcalde de Jerez de la Frontera, comunicándole que el Ministerio de la Gobernación, a través de la Dirección General de Sanidad, ha emprendido la tarea de conseguir en la segunda quincena de noviembre y en el mes de diciembre llevar a cabo una campaña nacional antipoliomielítica "de alcance muy superior a las que hasta ahora se han realizado". Especifica también que la vacuna que se va a administrar es la vacuna Sabin, por vía oral, "con la que será posible no solo obtener la inmunidad de todos los niños vacunados sino, de forma especial, la erradicación de la enfermedad de nuestra Patria". La carta del Gobernador al Alcalde jerezano aclara que la administración de la primera dosis (tipo I de la vacuna) incluye a los niños de dos meses a siete años de edad. Entre los argumentos de Guillén Moreno destaca la necesidad de crear conciencia en la población de que desaparezca esta enfermedad de España ya "que produce un promedio de 200 muertos y de 2.000 inválidos cada año, con los consiguientes daños físicos, morales y económicos". Por todo ello, el objetivo al que se aspira es acercarse al 100\% de los niños vacunados, insistiendo en que la vacunación se debe llevar a cabo con absoluta independencia de que los niños sean o no vecinos de Jerez de la Frontera. Guillén Moreno anuncia al Alcalde de Jerez que próximamente recibirá unas fichas u "hojas individuales" para registrar los datos de los niños. Para realizar la tarea de cumplimentar las fichas se demanda la colaboración desinteresada de los parientes de los niños, de los maestros, de las divulgadoras rurales, afiliadas a la Sección Femenina, sacerdotes, o cualquier persona idónea que se ofrezca para ello, "siempre que escriba en forma bien legible". Entre los datos que se deben consignar en la ficha destacan los siguientes: provincia, localidad, nombre y apellidos del niño, sexo, edad, número cartilla "S.O.E" (si es beneficiario del mismo), lugar de nacimiento, domicilio habitual, y si el niño ha recibido inyecciones de vacuna contra la poliomielitis, "a pesar de lo cual debe tomar ahora la vacuna por vía bucal". Asimismo se debe anotar la organización que lo vacunó: Sanidad Nacional, "S.O.E." (Seguro Obrero de Enfermedad) u "Otros”, apuntando en la casilla correspondiente el número de inyecciones de vacuna que haya recibido el niño. Esta ficha debe guardarla una persona responsable, pariente o no, quien la entregará al equipo de vacunación en el momento de presentarse el niño para ser vacunado. Guillén Moreno insiste en que, durante la distribución de estas hojas o fichas, debe aprovecharse para que todos los padres de familias o encargados sean 
informados de la Campaña, "de su carácter gratuito y de sus evidentes ventajas, destacando la responsabilidad moral en que incurrirán quienes no vacunen a sus hijos, dejándoles expuestos a contraer tan grave enfermedad" (Legajo 1.929, expediente 36.654, AMJ).

El 20 de noviembre de 1963, el Jefe provincial de Sanidad da instrucciones al Jefe local de Sanidad de Jerez de la Frontera, indicándole que el comienzo de la campaña es el día 25 de noviembre a las nueve de la mañana, solicitando además la colaboración en la misma de los médicos de Asistencia Pública Domiciliaria y de los médicos libres, así como de los alguaciles y de la guardia civil en los caseríos para reparto y cumplimentación de las fichas, impresos que se podían recoger en el Negociado de Beneficencia y Sanidad del Ayuntamiento jerezano. Entre las instrucciones que el Jefe provincial de Sanidad indica al Jefe local de Sanidad destaca también la necesidad de buscar locales para la vacunación, que sean céntricos y que estén bien comunicados, y que tengan puerta de entrada y de salida para facilitar la circulación fluida y evitar los retrasos en la vacunación.

El 22 de noviembre el alcalde de Jerez, Tomás García Figueras, convocó con carácter urgente, en el salón de las Casas Consistoriales, a los maestros de las Escuelas Nacionales y Privadas, así como representaciones de los organismos colaboradores, de las alcaldías rurales y de las entidades locales menores, que debían enviar a un representante a la reunión. Se procedió, en el transcurso de la organización de la Campaña, a realizar un inventario de las escuelas, anotándose el nombre del director, dirección de la misma y los grados que se impartían, todo ello con la finalidad de localizar al mayor número de niños a efectos de que recibieran la vacuna oral Sabin.
El Alcalde, en esos días, también envió una carta a los directores de Radio Jerez y del periódico La Voz del Sur, para que se le diera la mayor difusión a la campaña. Precisamente este periódico nos ha proporcionado información sobre la organización y el desarrollo de la misma. La Voz del Sur, en su edición del día 22 de noviembre de 1963, publicó dos noticias relacionadas con la vacunación que se iba a llevar a cabo. La primera titulada "Campaña Nacional Antipolio", de carácter divulgativo, señala que esta campaña comienza en la provincia de Cádiz, y en otras provincias españolas, el lunes 25 de noviembre, siguiendo posteriormente con otro grupo de provincias el día 2, concluyendo el 9 de diciembre en Madrid y Barcelona. Se señala que la campaña es completamente gratuita y que su objetivo es "establecer una barrera contundente contra la enfermedad (...) de manera que cada núcleo de población importante, en el plazo de unos días, tenga vacunados más del noventa por ciento de los niños de las edades comprendidas en la campaña...". Se apunta también que en realidad la campaña comenzó el 14 de mayo en las provincias de León y de Lugo donde "no hubo incidente, ni se ha producido una sola reacción, quedando plenamente demostrado que la vacuna con virus vivo, tipo Sabin es totalmente inofensiva". Con este artículo en el periódico se trata de divulgar la campaña en Jerez y de tranquilizar a la población sobre cualquier suspicacia que se pudiera tener sobre la vacuna. Pero ese mismo día, en la sección del periódico "Jerez, cada día", se da noticia de la convocatoria en la Alcaldía de todos los maestros de escuelas nacionales y privadas para recibir instrucciones. Y se precisa que la Delegación Provincial de Sanidad, a través del delegado en Jerez, Antonio Berengena del Rey, comunica que la vacunación de forma intensiva se llevará 
a cabo entre los días 25 al 27 de noviembre por "un equipo médico desplazado desde Madrid". El día 23 en la misma sección del periódico se da noticia de que se han habilitado las guarderías y hogares de la Sección Femenina para la campaña. En cuanto a las fichas quedarán en poder de las familias de los niños, que la presentarán en el centro de vacunación cumplimentadas, por ellos mismos o con la ayuda de los maestros. Los días 25, 26 y 27 se desplazarán a Jerez "los equipos médicos designados por la Jefatura Provincial de Sanidad”. Asimismo se aclara que la vacuna "por vía bucal deben tomarla también los niños ya vacunados o que estén vacunándose por inyecciones con vacuna Salk. La protección que confiere la vacuna Sabin es más duradera; en todo caso completa los efectos de aquella”. Y, por último, se señala en el periódico que los días señalados y en horario de 10 a 14 horas y de 16 a 20 horas se llevarán a cabo las vacunaciones en los siguientes lugares de la ciudad de Jerez:

- Hogar de "José Antonio" (calle Zaragoza, 40).

- Guardería Infantil “San Carlos” (calle Lealas, frente al cine).

- Hogar Azul (Calle Vicario, entrada por Ronda Muleros).

- Centro Comarcal de Higiene (calle Cristal, 1 y 3$)$.

Aunque el día 26 de noviembre, el delegado de Beneficencia, comunicó en un escrito que se realizarían las vacunaciones "para mayor facilidad”, además de en los lugares referidos, en los siguientes: Escuela Unitaria de Niñas (Parroquia de la Vid), Casa de Socorro (calle Arcos) y Guardería Infantil (Barriada Federico Mayo).

Pero también había que realizar las vacunaciones, y esto era más complejo, en la campiña jerezana. El Delegado de Beneficencia señaló los días y los centros en que vacunarían los equipos de la Jefatura provincial de Sanidad:

- Jueves, 28 de noviembre: Guadalcacín del Caudillo, Colonia de Caulina, Estella del Marqués, La Guareña, Barca de la Florida, San Isidro del Guadalete, El Torno, Torrecera y José Antonio.

- Viernes, 29 de noviembre: San José del Valle, El Mimbral y Tempul.

- Sábado, 30 de noviembre: Desde la Escuela de la Jarda se desplazarán los equipos a los núcleos urbanos más poblados, y también en el Charco de los Hurones.

- Lunes, 2 de diciembre: El Torno, en la carretera de Medina, La Ina, Fuente Rey, Mesas de Asta y El Majuelo.

- Martes, 3 de diciembre: Santos Inocentes (carretera de Sevilla), La Parra, El Portal, Alcántara y Nueva Jarilla.

- Miércoles, 4 de diciembre (último día de vacunación): Las Tablas.

Los resultados de la primera fase de la campaña no tardan en comunicarse, tanto a través de carta del Jefe de Negociado de Beneficencia o a través de la propia prensa. En la referida carta, fechada en Jerez el 4 de diciembre de 1963, se consigna que en total la campaña ha durado siete días, desde el 25 de noviembre al día 3 de diciembre, estableciéndose los centros de vacunación, pero también "puestos secundarios" en toda la campiña, "incluidas Barriadas rurales y Entidades Locales Menores". De manera, que según los datos oficiales, en Jerez de la Frontera y su término, "ha sido un éxito rotundo, pasando de 22.000 el número de niños vacunados, cuando los cálculos que de Madrid traían los equipos cifraban, 12.500 vacunaciones en número alzado".

El día 4 de diciembre, el Alcalde, Tomás García Figueras, también comunica el éxito y señala la colaboración desinteresada de padres, tutores, religiosos, maestros, directores 
de grupos y encargados de escuelas nacionales y privadas, así como de Auxilio Social, Sección Femenina, Alcaldes de Barriadas Rurales y Entidades Locales Menores, no olvidándose de la prensa y de la radio local. El alcalde también señala la cifra de más de 22.000 niños vacunados. Pero en su carta, en un comunicado a la prensa y a la radio, señala un matiz que creemos interesante consignar para conocer mejor los detalles de organización de la primera fase de la campaña de vacunación en Jerez:

"Como la inclemencia del tiempo de estos últimos días, ha podido dar lugar a que algunos niños se hayan quedado sin vacunar, pueden hacerlo en la Barriada Rural de San José del Valle, La Barca de la Florida y en el Centro Comarcal de Higiene, calle Cristal 1 y 3, donde el equipo de la Jefatura Provincial de Sanidad ha dejado dosis suficientes para ello".

Como se puede comprobar fue grande el esfuerzo realizado en pocos días para llegar a todos los puntos del término municipal de Jerez de la Frontera. Y muchas las personas que participaron. Al finalizar la primera fase de la campaña, el Jefe provincial de Sanidad de Cádiz escribe al Alcalde de Jerez, el día 11 de diciembre de 1963, agradeciendo su colaboración y la del doctor don Antonio Berengena, Jefe local de Sanidad, corroborando también el éxito "de la Campaña en la Provincia y en Jerez". Añadiendo el Jefe provincial de Sanidad: "Igualmente me complace manifestar a V.E. que en el Resúmen que esta Jefatura prepara para enviar a la Dirección General de Sanidad, hará especial mención de la diligencia y eficacia del Excmo. Ayuntamiento de Jerez de la Frontera" (Legajo 1.929, expediente 36.654, AMJ).

\subsection{La segunda fase de la campaña de vacu- nación (30 de marzo al 8 de abril de 1964)}

El Alcalde de Jerez de la Frontera, en el mes de marzo de 1964, recibió un telegrama del
Gobernador Civil anunciándole el comienzo inmediato de la segunda fase de la Campaña Nacional de Vacunación Antipoliomielítica, "debiendo esa Alcaldía prestar máxima colaboración a Jefatura Provincial de Sanidad y dispondrá que Policía Municipal preste servicios de mantenimientos, orden en todos los puestos de vacunación. Acúseme recibo".

El periódico $\mathrm{La} \mathrm{Voz} \mathrm{del} \mathrm{Sur,} \mathrm{del} \mathrm{día} 27$ de marzo de 1964, en su sección "Jerez, cada día", anuncia que la segunda fase de la campaña nacional contra la poliomielitis se iniciará el lunes 30 de marzo. Recuérdese que en esta ocasión se hizo con VPO trivalente de poliovirus 1, 2 y 3 (Pachón del Amo, 2004), e igualmente en niños con edades comprendidas entre los dos meses y los siete años. Se insiste en el periódico, en la edición del día 7 de abril, que "ningún niño debe quedarse sin vacunar". En esta ocasión visitó Jerez el Jefe provincial de Sanidad, acompañado del doctor Aljama, jefe del equipo móvil de vacunación antipolio que actúa en la ciudad. El mismo periódico, el día 8 de abril, anuncia que es el último día de vacunación, habiéndose vacunado hasta ese momento en la ciudad 12.433 niños, de los cuales 7.043 recibieron la vacuna en un solo día. Se insiste por parte de las autoridades, a través de la prensa y de la radio, con el objetivo de incentivar la campaña de vacunación, en el hecho "que desde que se administró la dosis anterior no se ha producido ni un solo caso de poliomielitis en la provincia entre los niños vacunados".

En esta segunda fase se cuenta con la experiencia de la primera y observamos que se repiten algunos aspectos. La organización de la campaña está en manos de las jefaturas provincial y local de Sanidad, y por supuesto de la Alcadía. De hecho la primera autoridad municipal, a través de una carta a los medios de comunicación, recordó que tanto los padres o parientes de los niños, como los maestros, las 
afiliadas a la Sección Femenina, los religiosos o cualquier persona idónea debían prestar su colaboración desinteresada, rellenando las fichas que se facilitaban en el Negociado de Beneficencia de la Secretaría Municipal. Como se puede apreciar, en buena medida, se repiten los esquemas de la organización de la primera fase de la Campaña.

La campaña de vacunación en la población de Jerez se llevó a cabo en los días señalados, en horarios de 9 a 13 horas y de 16 a 19 horas, utilizándose los mismos centros que hemos citado ya para la primera fase, añadiéndose a estos el local de la Cruz Roja (calle 18 de julio no 17). Y en lo que se refiere al término municipal, que por su dispersión ofrecía una mayor dificultad, se organizó de manera análoga a la fase anterior. Señalamos a continuación los días y sitios en que fueron vacunados los niños en estos lugares, que fueron divulgados a la población a través del periódico "La Voz del Sur" y suponemos que también a través de la radio local (Legajo 1.929, expediente 36.654, AMJ):

- Lunes, 30 de marzo: Estella del Marqués, Guadalcacín del Caudillo, Nueva Jarilla y Alcántara.

- Martes, 31 de marzo: La Guareña, San Isidro del Guadalete, Barca de la Florida, El Torno, Torrecera, José Antonio, Venta de San Miguel y San José del Valle.

- Jueves, 2 de abril: El Torno y carretera de Medina, Fuente del Rey, El Majuelo, Mesas de Asta, Los Santos Inocentes, El Portal y Las Tablas.

Estos son los días estipulados en principio para vacunar en esos puntos del término municipal jerezano, pero en documentación complementaria se puede comprobar que el día 2 abril vacunaron en Las Abiertas, Albadalejo, Barca de la Florida y Las Cuevas; el día 3, en Charco de los Hurones, Guadalcacín y Casa Blanca; el día 4, en Nueva Jarilla, Mendosilla, Parrilla, Portal y Quinientas; el día 6, en Romerales, Romero, San Isidro de Guadalete y San José del Valle, y el día 7, en Tabajete, Torno y Torrecera (Legajo 1.929, expediente 36.654, AMJ).

Una vez finalizada la segunda fase de la Campaña, la Alcaldía de Jerez, con fecha de 13 de abril, comunicó que en el Centro Comarcal de Higiene (calle Cristal 1 y 3), en horas de 10 a 12 de la mañana, se seguiría administrando la segunda dosis a los niños con edades comprendidas entre los dos meses y los siete años, "que por cualquier causa hayan dejado de tomarlas o que no se encuentren vacunados ni en su primera dosis, cuyo plazo terminará improrrogablemente el próximo sábado día 18 de los corrientes" (Legajo 1.929, expediente 36.654, AMJ).

La documentación consultada en el Archivo Municipal de Jerez de la Frontera contiene información numérica de las vacunaciones realizadas en la ciudad y en la campiña, en la segunda fase (marzo-abril de 1964), en la cual se especifica las localidades y los niños vacunados. Según nuestros cálculos, a partir de la citada documentación, se vacunaron en esta segunda fase de la Campaña unos 24.000 niños (Legajo 1.929, expediente 36.654, AMJ). Recuérdese que en la primera fase de la Campaña (noviembre-diciembre de 1963) apuntamos la cifra de 22.000 .

Como hemos podido apreciar la Campaña de vacunación contra la polio en Jerez de la Frontera (1963-1964), en sus dos fases, fue llevada a cabo con orden y con instrucciones precisas; como en el resto del país, al ser una campaña organizada por la Dirección General de Sanidad, tuvo su apoyo fundamental en las jefaturas provinciales y en las jefaturas locales de Sanidad, en este caso concreto en las de Cádiz y Jerez, respectivamente. Se aprecia a través 
de la documentación burocrática del municipio jerezano y de la prensa de la localidad que fueron días intensos y de mucho trabajo por parte del personal sanitario y municipal, pero también para otros colectivos como los maestros, incluso voluntarios, que ya hemos señalado. Hay aspectos sobre los que no hemos localizado documentación específica; por ejemplo, sobre la forma en que se hizo el transporte de las vacunas por los equipos móviles y sobre su conservación y mantenimiento en buen estado. Sobre este particular Florencio Pérez Gallardo ofrece información en la memoria de la campaña (Rodríguez Sánchez, 2010).

1.3. Notas sobre la campaña de vacunación contra la polio y otras enfermedades en Jerez de la Frontera (1965)

Con lo apuntado podríamos dar por con-cluido nuestro estudio sobre las dos fases de la Campaña de 1963 y 1964 en Jerez de la Fron-tera. Pero también nos planteamos en esta in-vestigación la necesidad de localizar documen-tación que permita comprobar si este trabajo intenso contra la enfermedad, realizado en los años apuntados, tuvo continuidad en Jerez de la Frontera, al menos, en el año 1965. Y en esta línea hemos procedido a la búsqueda de los ci-tados documentos, acompañándonos la fortuna al localizar un expediente que nos permite rea-lizar un esbozo de lo acontecido en el referido año (Legajo 1.929, expediente 36.659, AMJ). En 1965 se puso en marcha en Jerez de la Frontera, la "Campaña Nacional de Vacuna-ción Antipolio, Difteria, Tosferina y Tétanos", y se realizó en dos fases, segúnconsta en el expe-diente consultado: la primera, del 22 de febre-ro al 11 de marzo, y la segunda del 5 al 10 de abril (Legajo 1.929, expediente 36.659, AMJ). Parece que en esta ocasión, la experiencia de la campaña del año anterior, hace que el Jefe provincial de Sanidad escriba, el día 8 de ene- ro, al Alcalde de Jerez solicitando se entregue al Director del Centro Comarcal de Higiene de la ciudad un censo infantil, "toda vez que en dicho Centro será montado un puesto de vacunación, atendido directamente por el personal adscrito al mismo". En otra carta de la misma fecha informa al Alcalde sobre el comienzo de la citada campaña, que en esta ocasión, como hemos indicado, será contra la difteria, la tos ferina, el tétanos y la poliomielitis. La campaña se llevará a cabo entre los días 22 de febrero y el 11 de marzo. Será gratuita y los niños "sujetos" a la misma serán los mayores de tres meses y menores de tres años para la difteria, la tos ferina y el tétanos, y para la poliomielitis por vía oral "los comprendidos en las mismas edades que no hayan sido anteriormente vacunados por la vacuna Sabin...”. En cuanto a los encargados de administrarlas, en los casos de "agrupaciones humanas con médico titular", se encargarán los médicos de la Asistencia Pública Domiciliaria (APD), con la supervisión del Jefe local de Sanidad, y auxiliados por los practicantes y las comadronas de APD y hospitales municipales y Casas de Socorro. En los casos de "agrupaciones humanas sin médico titular distantes más de tres kilómetros del casco urbano" serán vacunados por los médicos, practicantes y comadronas de APD o "por equipo de esta jefatura”. Se emplearán para la vacunación cuatro horas diarias (dos por la mañana y dos por la tarde), y el número de locales serán los que estime oportuno el Alcalde. Se anuncia como fecha de administración de la segunda dosis a partir del día 5 de abril. Para todo ello es crucial que el Ayuntamiento tenga disponible un censo infantil antes del día 1 de febrero con los "niños nacidos en 1962, 1963 y 1964, residentes en el término municipal", expresando en el mismo los nombres y apellidos, domicilios, fechas de nacimiento y "dejando espacio en blanco 
para poder señalar si se vacunan de la tripe o de polio" (Legajo 1.929, expediente 36.659, AMJ). Una vez realizados los cálculos para el censo desde la Secretaría del Ayuntamiento se apunta "12.000 niños las sumas de los 3 años". Se calcula que "unos 4.000 niños por año".

Nuevamente el Alcalde anuncia, con fecha de 13 de enero, que para esta campaña se requerirá la colaboración de la Sección Femenina, de Acción Católica, de los maestros y de personal voluntario. En esos días los alcaldes pedáneos o de barrios de El Torno, Guadalcacín, Torrecera, Nueva Jarilla, El Portal, etc., comunican de forma aproximada el número de niños nacidos en los años requeridos y los locales disponibles para la vacunación. El día 23 de enero, el Presidente de la Comisión de Beneficencia y Sanidad recibe una carta del Laboratorio Municipal de Higiene de Jerez, en la que se comunica que se ha recibido un telegrama del Jefe provincial de Sanidad para que se suspenda la vacunación antivariólica en niños mayores de tres meses y menores de tres años "hasta nueva orden". Esta medida la aclararemos en este trabajo más adelante.

El Alcalde, el Teniente de Alcalde de Beneficencia y Sanidad, y el Jefe local de Sanidad se reúnen el día 20 de enero para estudiar el em- plazamiento de los locales para llevar a cabo la vacunación. En febrero de 1965, Miguel Primo de Rivera y Urquijo, Alcalde de Jerez, y Joaquín Albuín Gómez, Delegado de Beneficencia y Sanidad, firman un Bando en el que comunican a la población los Centros donde se administrarán las vacunaciones (figura 3).

En el Bando también se hace constar los días y lugares en que se realizarán las vacunaciones en la campiña jerezana. En otro Bando, también del mes de febrero, se establecen los turnos de los médicos y de los practicantes que deberán administrarlas, no constan en este documento nombres de matronas para realizar esta labor, aunque sí se insta a una practicante, la Srta. Martín de Castro, junto con otros compañeros, a que no pierdan el contacto con la Jefatura local de Sanidad por si fueran necesarios sus servicios. No citaremos los nombres de los profesionales, médicos y practicantes, para no alargar en demasía este artículo, pero sí debemos consignar que, por ejemplo, Luis Encina González, Decano del Cuerpo de Médicos de APD, tenía programada su labor de vacunación en la Barriada de la Asunción.

El 29 de enero, el Jefe provincial de Sanidad escribe nuevamente al Alcalde de Jerez y realiza unas precisiones que consideramos interesante

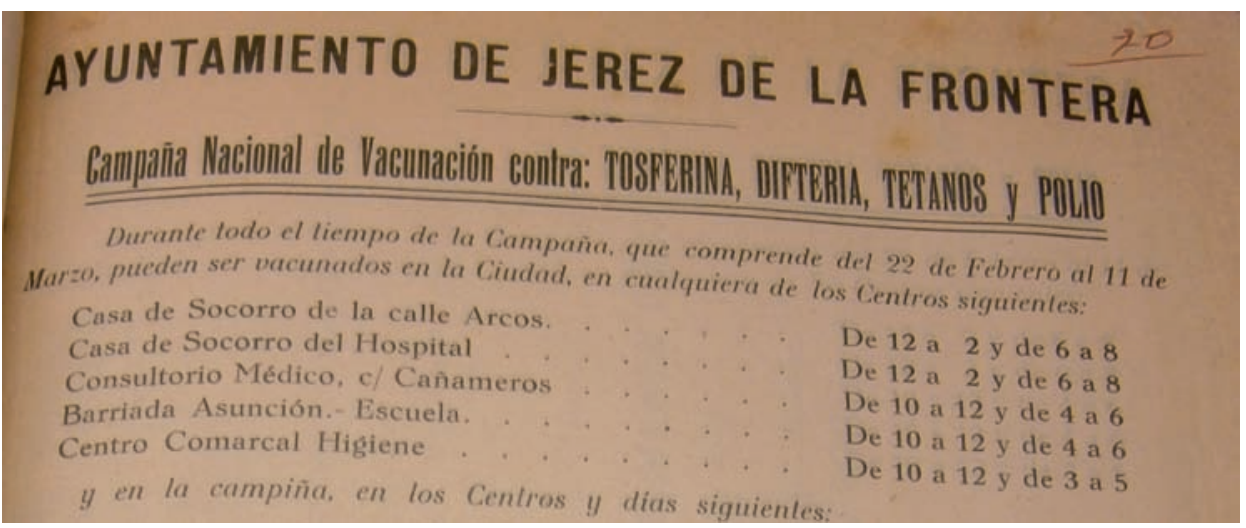

Figura 3: Fragmento del Bando firmado en febrero de 1965 por el Alcalde de Jerez, Miguel Primo de Rivera y Urquijo, en el cual constan los centros para la campaña de vacunación en la ciudad de Jerez. Fuente: (Legajo 1.929, expediente 36.659, AMJ). 
apuntar; por ejemplo, se corrobora que la edad de los niños que van a recibir la "vacuna triple" deben ser "niños mayores de 3 meses y menores de 3 años", y con respecto a la vacuna Sabin encontramos mayor precisión que en el anterior apunte que hemos realizado, en lo que se refiere a esta campaña de 1965: "A los mayores de 3 meses y menores de un año". Se insiste que en cada puesto de vacunación deberá haber un médico y un practicante, comadrona o enfermera, "todos ellos de los servicios oficiales o titulares aunque no se debe prescindir de la colaboración desinteresada que ofrezca cualquier otro profesional sanitario". En este sentido, como hemos apuntado ya, hemos visto que fueron asignados a los puestos de vacunación médicos y practicantes, pero no hemos observado la participación de comadronas o enfermeras. Otra cuestión más plantea el Jefe provincial de Sanidad: el Alcalde debe comunicar a la Jefatura provincial de Sanidad las neveras, tanto oficiales como particulares (siempre que le ofrezcan las debidas garantías), en que pueden guardarse las vacunas para realizar con eficacia la Campaña en Jerez. El día 2 de febrero, el Teniente de Alcalde, Delegado de Beneficencia y Sanidad, detalla al Jefe provincial de Sanidad, los lugares en que se encuentran las neveras donde pueden conservarse las vacunas:

- En la ciudad de Jerez: Las neveras del Hospital Municipal de Santa Isabel ("muy amplia”), del Laboratorio Municipal de Higiene y del Centro Comarcal de Higiene.

- En la campiña jerezana: En la Barca de la Florida (las neveras de los domicilios particulares del médico y del Secretario del Ayuntamiento, y la nevera del "Bar Bolilla”). En San José del Valle (la nevera del domicilio particular del médico y "además existen en esta Barriada dos bares con frigorifico").
En cuanto a la administración de la vacuna triple se hará en inyección intramuscular de 0,5 centímetros cúbicos en región glútea, previa desinfección con "alcohol yodado", mientras que la vacuna Sabin se administrará "en forma igual que la campaña anterior". Como ejemplo apuntamos la relación del material que se recibió en el puesto de vacunación de la Barca de la Florida, en febrero de 1965: 2 jeringas de 3 centímetros cúbicos; 432 dosis de vacuna trivalente; 150 dosis de vacuna antipolio; 50 cucharillas; dos litros de alcohol yodado; 1 kilogramo de algodón hidrófilo; 150 terrones de azúcar; 2 cajas de aguas (24 agujas); 500 fichas individuales y 5 hojas de relación nominal.

En esta campaña también se utilizó Radio Jerez y el periódico La Voz del Sur para divulgar los comunicados del Alcalde o de otras autoridades municipales y sanitarias, sobre este particular se pueden consultar los periódicos de los días 9, 11, y 16 de febrero, que insisten por ejemplo en la gratuidad de la campaña. El día 23, la prensa jerezana aclara las edades para las vacunaciones de los niños, que ya hemos consignado anteriormente, pero también matiza lo siguiente: "En cuanto a los mayores de estas edades pueden también vacunarse, pero corriendo de su cuenta la adquisición de las vacunas, ya existentes en las farmacias". Igualmente se apuntan algunas cuestiones apelando a la responsabilidad de los padres: la existencia de casos de muerte en España "en niños no vacunados por abandono de sus padres, pese a la obligatoriedad por orden ministerial del año 1943, por cuanto a la difteria se refiere". Y se inserta una pequeña nota en la prensa de ese día referida a la poliomielitis: "Ya no debe volver a España la poliomielitis. Vacunad a los niños que antes no recibieron la vacuna Sabin y contribuiréis al bienestar de la infancia”. 
En La Voz del Sur, de 24 de febrero, se publicó un amplio artículo del Dr. Gimeno de Sande titulado "Campaña Nacional de Vacunación contra la difteria, tosferina, tétanos y poliomielitis”. Destaca una frase de este artículo:

"Nosotros también confiamos más en la persuasión y en la elevación del nivel cultural sanitario, que en la obligatoriedad, y buen ejemplo ha sido el rotundo éxito en la pasada campaña contra la Poliomielitis al vacunarse prácticamente el 100 por 100 de los niños, a cuyo éxito tanto contribuyó una Campaña de Propaganda bien llevada por la Televisión, Radiodifusión y Prensa".

El citado periódico, los días 28 de febrero y 3 de marzo, insiste en la obligatoriedad de la vacunación, también en que a finales del mes de febrero se han vacunado en España "más de medio millón de niños" en los cinco primeros días de la Campaña. En lo que se refiere a Jerez de la Frontera, el periódico anuncia una prórroga los días 9, 11 y 14 de marzo para la aplicación de la vacunación, "por el mal tiempo de los últimos días".

El día 12 de marzo, La Voz del Sur realiza un balance de la primera fase de la Campaña de vacunación de 1965, subrayando que está a punto de finalizar y que el número de vacunados mayores de tres meses y menores de tres años en España es de 1.176.331, destacando que "409.365 menores de un año, han recibido además la vacuna Sabin contra la poliomielitis, lo que representa un 70 por 100 de los comprendidos en aquellas edades". Y se insiste además en que aún quedan días para que termine la Campaña. En lo que se refiere a Jerez de la Frontera podemos ofrecer datos estadísticos de las vacunaciones efectuadas entre los días 22 de febrero y 11 de marzo de 1965, a partir de un documento en el que no consta membrete ni firma (tabla 5).

\begin{tabular}{|c|c|c|}
\hline DÍA Y MES & $\begin{array}{c}\text { "TRIVALENTE" } \\
(\mathbf{s i c})\end{array}$ & ANTIPOLIO \\
\hline 22 febrero & 203 & 76 \\
\hline 23 febrero & 326 & 126 \\
\hline 24 febrero & 578 & 216 \\
\hline 25 febrero & 627 & 303 \\
\hline 26 febrero & 329 & 132 \\
\hline 27 febrero & 343 & 116 \\
\hline 1 marzo & 129 & 40 \\
\hline 2 marzo & 412 & 133 \\
\hline 3 marzo & 586 & 199 \\
\hline 4 marzo & 304 & 99 \\
\hline 5 marzo & 402 & 132 \\
\hline 6 marzo & 184 & 70 \\
\hline 8 marzo & 377 & 137 \\
\hline 9 marzo & 427 & 161 \\
\hline 10 marzo & 224 & 28 \\
\hline 11 marzo & 354 & 112 \\
\hline TOTAL & $\mathbf{5 . 8 0 5}$ & $\mathbf{2 . 0 8 0}$ \\
\hline
\end{tabular}

Tabla 5: Número de vacunaciones de "trivalente" (sic) y antipolio en Jerez de la Frontera (22 de febrero al 11 de marzo de 1965). Obsérvese que el funcionario que elaboró este documento escribe "trivalente" cuando debía referirse a la "triple" (Difteria, tétanos y tos ferina). Fuente: Legajo 1.929, Expediente 36.659. Campaña de vacunación antipolio, difteria, tos ferina y tétanos, 1965 (AMJ).

Los días 27, 29 de marzo y 2 de abril, La Voz del Sur, incluye Bandos del Alcalde, Primo de Rivera, y noticias anunciando que la segunda fase de la Campaña se llevará a cabo entre los días 5 y 14 de abril. Podemos apuntar que en el Centro de Vacunación de la Casa de Socorro de la calle Arcos, entre el 22 de febrero y el 18 de abril de 1965, ambos inclusive, se administraron 2.272 vacunas de la "triple" y 711 de la polio (Legajo 1.929, Expediente 36.659, AMJ). Datos que solo ofrecen una panorámica parcial de las vacunaciones efectuadas en Jerez de la Frontera en ese periodo de tiempo, ya que no incluye las estadísticas de otros centros de vacunación.

Conviene precisar también algunos aspectos subrayados por el Jefe provincial de Sanidad de Cádiz, en su extenso comunicado del día 29 de enero de 1965 al Alcalde de Jerez; el primero de ellos es que el haber padecido la 
tos ferina no constituye contraindicación alguna para esta vacunación y que la vacuna triple solo está contraindicada en los niños que padezcan procesos febriles, eczema, piodermitis generalizadas, lesiones cerebrales o convulsiones, y en los casos en que los niños estén sometidos a tratamiento con corticosteroides. En cuanto a la poliomielitis debemos subrayar un aspecto que ha llamado nuestra atención del escrito del Jefe provincial de Sanidad (Legajo 1.929, expediente 36.659, AMJ):

"Los niños menores de un año y mayores de tres meses cuyos padres rehúsen que les sea administrada la vacuna triple quedarán excluidos de la administración de la vacuna SABIN hecho que conviene sea recogido en los bandos y propaganda”.

No hemos podido aclarar, en lo que se refiere a la vacuna Sabin, si en Jerez de la Frontera se utilizó la elaborada por el Laboratorio Pfizer, o la del Laboratorio Wellcome o la del Laboratorio Ibys. En cambio, en el Archivo Municipal de Cádiz hemos encontrado un prospecto de Laboratorio Ibys con el nombre comercial de "Virusvacuna antipoliomielítica oral. Tipo Sabin” (Caja 3.834, AMC). Este laboratorio presentaba diversos envases: monovalente (tipo I), bivalente (tipos 2 y 3 ) y trivalente (tipos 1, 2 y 3 ). Se aclara en el prospecto que la vacuna puede conservarse por los menos seis meses entre $2^{\circ}$ y $10^{\circ}$, aunque puede ser expuesta excepcionalmente durante cortos periodos de tiempo a $25^{\circ} \mathrm{C}$. Se apunta también que esta vacuna "no produce reacción (...) y que no hay contraindicaciones en su uso, excepto en las infecciones agudas y en las diarreas (porque pueden ser debidas a un enterovirus que interferiría la vacunación". Asimismo se "aconseja dejar un intervalo de 21 días antes de realizar otras vacunaciones con virus vivos, tales como la vacunación antivariólica y la antiamarílica.
Sin embargo, la vacuna antipoliomielítica por vía oral se puede administrar simultáneamente con vacuna antitetánica, antidiftérica y antipertusis, con garantía y efectividad”. Estas matizaciones pueden hacernos entender el motivo por el que el Jefe provincial de Sanidad de Cádiz envió a Jerez de la Frontera un comunicado suspendiendo la vacunación antiavariólica en los niños mayores de tres meses y menores de tres años "hasta nueva orden".

\section{EPÍLOGO}

En la década de los cuarenta, cincuenta y sesenta existió una gran preocupación en España, en muchas familias, por la gravedad creciente de la poliomielitis, tanto en lo referido a la morbilidad como a la mortalidad. Tan solo hay que estudiar la tabla 2 que ofrece datos de los años 1949 a 1967, además de a los autores citados a lo largo del texto, para comprender que era un problema de salud pública al que había que poner remedio. Un remedio que llegó en forma de vacuna, primero la de Jonas Edward Salk y después la de Albert Bruce Sabin, sobre las cuales hemos precisado a lo largo del trabajo su utilización y sus diferencias.

No cabe duda de que la campaña de vacunación de finales de 1963 y principio de 1964, en España, supuso un antes y un después en la lucha contra la enfermedad; muchos profesionales (médicos, practicantes y enfermeras), así como voluntarios, participaron para que la vacuna Sabin llegara a los niños españoles, aspecto que hay que subrayar. Desde el punto de vista de la investigación y puesta en marcha de la campaña, debe destacarse la labor del médico gaditano Florencio Pérez Gallardo, que también tuvo una participación notable en la campaña piloto llevada a cabo previamente en las ciudades de León y Lugo, que como hemos visto en este trabajo ha sido estudiada en 
profundidad y de forma crítica por RodríguezSánchez y Seco Calvo (2009).

La referida campaña piloto, y la propia campaña nacional de vacunación contra la poliomielitis puesta en marcha en 1963 y 1964, incluso las campañas posteriores llevadas a cabo en los años sesenta, requieren de más trabajos monográficos para conocer pormenores que quizás en la actualidad solo están esbozados, para ello hay que seguir insistiendo en el estudio de las fuentes manuscritas e impresas, pero también de las fuentes orales, y en esta línea vienen trabajando con solvencia varios investigadores en nuestro país, algunos de los cuales han quedado referenciado en la bibliografía de este artículo.

Ateniéndonos a la campaña de vacunación contra la poliomielitis de 1963 y 1964, en sus dos fases, se debe considerar que se pusieron en marcha cincuenta equipos móviles. García Orcoyen señaló, en noviembre de 1963, que con esta campaña se aspira "fundamentalmente a la erradicación de la enfermedad, como ya se ha conseguido con la viruela y el paludismo". El director del Centro Nacional de Virus, Florencio Pérez Gallardo, al presentar a los medios la primera fase de la campaña manifestó "que se había trabajado intensamente para conseguir que los equipos de vacunación alcancen a todos los municipios y lugares españoles". Entre los recursos humanos señaló el médico gaditano que se contaba para llevar a cabo la campaña con más de 150 médicos especializados, acompañados cada uno por dos o tres enfermeras, afiliadas a la Sección Femenina o colaboradoras, que "se distribuirán por todo el país para administrar la vacuna; con ellos cooperarán los nueve mil médicos titulares y la clase médica en general". En la presentación de la campaña se subrayó la necesidad de la colaboración por parte de los padres, maestros, directores de colegios y de orfelinatos (ABC-M, 15-XI1963), hecho que hemos podido comprobar en nuestro estudio de la campaña de vacunación en Jerez de la Frontera. Así, pues, en 1963, la Dirección General de Sanidad inició la primera de sus grandes campañas nacionales y en unos meses "se vacunaron a 4.631.154 niños mayores de dos meses y menores de ocho años (sic)". Lo que tuvo como consecuencia el descenso de la morbilidad que ya hemos indicado para los años 1964 y 1965 (ABC-S, 20-XII-1967). Recuérdese que en la primera fase de la campaña nacional fueron vacunados 4.400 .000 niños (95\% de la población) y en la segunda a 4.680 .000 (98\%) (Pérez Gallardo, Valenciano Clavel, Gabriel y Galán, 2013).

En la prensa se señaló con insistencia que no debía quedar ni un niño sin vacunar, mayores de dos meses y menores de siete años, además se destacó lo fácil de su administración al ser una vacuna oral que se dispensaba con un terrón de azúcar o con una cucharadita de agua o jarabe, de esta forma tan sencilla "quedan totalmente vacunados y en su intestino no se reproducirán jamás los poliovirus paralizantes $y$, por consiguiente, se rompe la cadena de propagación de los virus de la poliomielitis, desapareciendo el peligro de transmisión y el de padecer esta terrible enfermedad, que en muchas ocasiones producía la muerte del niño o lo dejaba deforme o incapacitado para toda la vida" (ABC-S, 29-III-1964).

Ya hemos expuesto en este artículo la preocupación, en cuanto a la morbilidad y a las escasas vacunaciones contra la poliomielitis que se estaban llevando a cabo en la provincia de Cádiz en la década de los cincuenta, sobre todo a partir de los escritos del Jefe provincial de Sanidad Francisco Aristoy; pero también Manuel Cruz Hernández, catedrático de Pediatría de la Facultad de Medicina de 
Cádiz, mostró su inquietud en un trabajo titulado "Consideraciones sobre las formas graves de poliomielitis en el último brote epidémico de Cádiz", apuntando que desde julio de 1957 a primeros de agosto de 1958, en los servicios de Pediatría y en el dispensario de la Jefatura provincial de Sanidad, fueron asistidos 104 enfermos, de los cuales 26 padecían "formas graves". El propio Cruz Hernández, en los años sesenta, debido a que la situación era preocupante (tablas 3 y 4), consiguió que la Diputación Provincial pusiera en marcha para la asistencia rehabilitadora y médica de los niños con poliomielitis, incluido el pulmón de acero, el "Centro San Acacio" (Herrera, 2012).

Juan del Rey Calero, actualmente miembro de la Real Academia Nacional de Medicina, que vivió el problema de la poliomielitis en los años sesenta, concedió una entrevista a Diario de Cádiz, en la que manifestó que en la citada década Cádiz tenía la mayor tasa de niños con poliomielitis, "casi 150 afectados de los 2.200 que existían en España". Rey Calero subraya el esfuerzo que se hizo en 1963 porque en algunas poblaciones de la provincia de Cádiz en los Ayuntamientos no existían las listas con los niños del pueblo y en los colegios había un porcentaje alto de absentismo, sobre todo en los barrios marginales, "por lo que era complicado localizar a los pequenos para vacunarlos". Rey Calero apunta que "conseguimos vacunar a todos los niños, con una cobertura superior al 95\%" (DC, 19-XI-2001). Unas cifras para la provincia de Cádiz que vienen a ser coincidentes con las apuntadas para el conjunto del país por Pérez Gallardo, Valenciano Clavel y Gabriel y Galán (2013).

Hay que tener en cuenta que después de la campaña de vacunación de 1963-1964 el número de casos de poliomielitis en España, según las cifras oficiales, se redujeron de 1.959, en el año 1963, a 193 en 1964 y a 70 en 1965 (tabla 2) (figura 4); aunque en los años 1966 y 1967 se vuel- ve producir un incremento a 308 y 362 casos respectivamente, circunstancia que motiva que algunos investigadores estén tratando de aclarar de qué manera se desarrollaron las campañas a lo largo de todo el segundo quinquenio de la década de los sesenta, intentando comprender si hubo relajación en las campañas de vacunación o si se incurrieron en defectos en su organización que habrían motivado que quedaran niños sin vacunar (Rodríguez Sánchez, 2014). Hecho que en otros contextos históricos y en otras circunstancias ha ocurrido en nuestro país, con respecto a la viruela, por ejemplo en el primer tercio del siglo XX (Herrera, 1990 y 2007; Sáinz Otero, 2007). En este aspecto compartimos la opinión de Rafael Nájera (2013a), que califica la campaña de vacunación con la vacuna Sabin (1963-1964):

"(de)...éxito indiscutible que debería haber dado paso a la eliminación en un corto período de tiempo, pero que, al relajarse la lucha contra la enfermedad, vacunación y vigilancia, permitió un repunte que arrastró la presencia de la polio en España durante 23 años. La cifra de 62 casos de 1965 no se va a mejorar hasta 1976 con 41 casos".

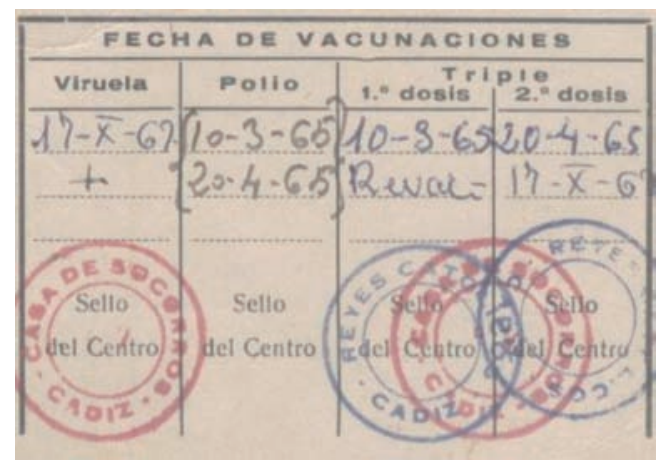

Figura 4: Detalle de una ficha de los servicios sanitarios del Ayuntamiento de Cádiz, en la que omitimos los datos personales del niño. Constan las vacunaciones recibidas contra la polio y la "triple" (1965), además de la vacuna de la viruela. Fuente: Archivo personal de F.H.R. 
En este trabajo hemos estudiado monográficamente la campaña de vacunación contra la poliomielitis de 1963 y 1964, en sus dos fases y con la vacuna Sabin, en Jerez de la Frontera; pero también hemos procurado localizar fuentes documentales que nos permitan comprender si en esta importante ciudad de la provincia de Cádiz hubo continuidad o no en la vacunación contra la enfermedad en el año 1965. En lo que se refiere a este año se ha subrayado como peculiaridad específica de la misma, que en España y también en Jerez de la Frontera se vacunó contra la poliomielitis, con la vacuna Sabin, pero también se incorporó a la campaña la vacunación contra la difteria, el tétanos y la tos ferina (DPT). En esta campaña, en lo que se refiere al conjunto del país, se alcanzó una cobertura de vacunación del 70\% y en lo que se refiere a la poliomielitis se observa que también hubo un descenso en la morbilidad (Pachón del Amo, 2004) (tabla 2). Todo lo cual indica que durante los años 1963 a 1965 se realizó un esfuerzo notable en la lucha contra la poliomielitis en España y también en Jerez de la Frontera, tanto en su núcleo urbano como en la campiña, tarea coordinada desde la Jefatura provincial de Sanidad de Cádiz que se apoyó en la Jefatura local de Sanidad, en las autoridades municipales, en los médicos, practicantes y enfermeras, en los maestros y en personas voluntarias de la localidad jerezana, que colaboraron también en la cumplimentación de las fichas, elaboradas para consignar los datos de los niños vacunados contra la poliomielitis, en la campaña de 1963-1964, pero también en la de 1965 en que la vacunación se llevó a cabo contra esta enfermedad, pero también como hemos indicado contra la difteria, la tos ferina y el tétanos.

A pesar de todo ello llama la atención, como hemos indicado, que en el conjunto del país se pasara de los 70 casos de poliomielitis del año
1965 a los 308 del año 1966 y a los 362 de 1967 (tabla 2); en lo que se refiere a la provincia de Cádiz se deben subrayar de forma significativa las 7 defunciones que se producen en el año 1971 (tabla 3) y el indicador de la morbilidad que en 1966 es de 3,4 y en 1969 de 2,97, mientras que en 1971 asciende a 3,72 (tabla 4).

No cabe duda de que éste y otros aspectos sobre la enfermedad requieren de un mayor número de investigaciones para conocer en plenitud los problemas que acontecieron, y para ello como hemos indicado hay que seguir recurriendo a las fuentes documentales de los archivos, pero también a las fuentes orales para conocer en su justa medida como se llevaron a cabo las campañas de vacunación, la vigilancia y en su conjunto la lucha contra la enfermedad (Rodríguez Sánchez, 2009, 2010, 2013b y 2014; Nájera, 2013a).

\section{AGRADECIMIENTOS:}

Agradezco al profesor Juan Antonio Rodríguez Sánchez, de la Universidad de Salamanca (uno de los mayores expertos en el estudio de la historia de la poliomielitis en España), sus comentarios, sugerencias y generosidad al proporcionarme bibliografía y datos estadísticos. Asimismo su estímulo para que llevara a término este modesto trabajo.

\section{FUENTES Y ARCHIVOS}

- Archivo Municipal de Jerez de la Frontera (AMJ):

- Legajo 1929. Expediente 36.653 (Beneficencia. Distribución sanitaria).

- Legajo 1929. Expediente 36.654 (Campaña de vacunación antipoliomielítica) (1963-1964).

- Legajo 1929. Expediente 36,659 (Beneficencia y Sanidad. Campaña de vacunación amtipoliomielítica, difteria, tos ferina y tétanos (1965).

- Periódico "La Voz del Sur" (Recortes de prensa localizados en Legajo 1929, expediente 36.654). Citamos a continuación los días y páginas consultados de este periódico: 22 de noviembre de 1963, pp. 3-4; 23 de noviembre de 
1963, p. 5; 27 de marzo de 1964, p. 6; 7 de abril de 1964, p. $5 ; 8$ de abril de 1964 , p. 5.

- Periódico "La Voz del Sur" (Recortes de prensa localizados en Legajo 1929, expediente 36.659). Citamos a continuación los días y páginas consultados de este periódico: 9 de febrero de 1965, p. 4; 11 de febrero de 1965, p. 5; 16 de febrero de 1965, p. 5; 23 de febrero de 1965, p. 4; 24 de febrero de 1965, p. 63; 28 de febrero de 1965, p. 4; 3 de marzo de 1965, p. 7; 12 de marzo de 1965, p. 3.

- Archivo Municipal de Cádiz (AMC):

- Caja 3.831. Partes estadísticos semanales. Estadística sanitaria 1956-1973. Contiene partes emitidos por el Jefe local de Sanidad (Ayuntamiento de Cádiz) Jefe provincial de Sanidad (Instituto provincial de Sanidad. Paseo de las Delicias, Olivillo, Cádiz).

- Caja 3.834. Beneficencia y Sanidad. Expediente y documentación “varia” de vacunaciones (1950-1964).

- Boletín Oficial de la Provincia de Cádiz (BOPC): 9 de enero de 1963 (No7): Orden de 27 diciembre de 1962 sobre la campaña de vacunación antipoliomielítca masiva durante los meses de enero a junio de 1963, p. 1; 19 de febrero de 1963 ( $\mathrm{N}^{\circ} 42$ ): Orden de 26 de enero de 1963 por la que se dictan normas en cuanto a las obligaciones y facultades de la Dirección General de Sanidad en materia de medicina preventiva (vacunación antipoliomielítica),p. 1.

- Biblioteca José Celestino Mutis (Cádiz):

- Se han consultado los siguientes números de Diario de Cádiz (DC): Diario de Cádiz: 25 de junio de 1961; 13 de septiembre de 1963, p. 6; 9 de mayo de 1963, p. 3; 19 de mayo de 1963, p. 3; 22 de mayo de 1963, p. 1; 19 de noviembre de 2001, p. 12.

- Instituto Nacional de Estadística:

- Libros del Movimiento Natural de la Población de España (1958-1975).

- Hemeroteca digital:

- Se ha consultado el periódico ABC de Madrid (ABC-M) y ABC de Sevilla (ABC-S):

- ABC-M, 2 de abril de 1958, edición de la mañana, p. 26. Disponible en: http://hemeroteca.abc.es/nav/Navigate.exe/hemeroteca/madrid/abc/1958/04/02/026.html (Consultado el 26 de julio de 2015).
- ABC-M, 23 de enero de 1959, edición de la mañana, pp. 31-32. Disponible en: http://hemeroteca.abc.es/nav/ Navigate.exe/hemeroteca/madrid/abc/1959/01/23.html (Consultado el 26 de julio de 2015).

- ABC-M, 15 de noviembre de 1963. Edición de la mañana, p. 60. Disponible en: http://hemeroteca.abc.es/nav/ Navigate.exe/hemeroteca/madrid/abc/1963/11/15/060. html (Consultado el 31 de julio de 2015).

- ABC-S, 29 de marzo de 1964. Edición de Andalucía, p. 95. Disponible en: http://hemeroteca.sevilla.abc.es/nav/Navigate.exe/hemeroteca/sevilla/abc.sevilla/1964/03/29/095. html (Consultado el 31 de julio de 2015).

- ABC-S, 20 de diciembre de 1967. Edición de Andalucía, p. 34. Disponible en: http://hemeroteca.sevilla.abc.es/nav/Navigate.exe/hemeroteca/sevilla/abc.sevilla/1967/12/20/034. html (Consultado el 31 de julio de 2015).

\section{BIBLIOGRAFÍA}

- Aguila Maturana, A. (2000). El debate médico en torno a la Rehabilitación en España (1949-1969). Tesis doctoral. Facultad de Medicina. Madrid: Universidad Complutense.

- Aguila Maturana, A., Álvarez Badillo, J.C., Miangolarra Page, L.P., Rodríguez Rodríguez, L.P. (2002). Influencia de las epidemias de poliomielitis sobre la rehabilitación en España (1949-1969). Rehabilitación (Madr), 36, 4249.

- Aristoy-Santos, F. (1959). Notas sobre la poliomielitis en Cádiz (Campaña de Vacunación)”. En Libro de Actas de la V Reunión Nacional de Sanitarios (pp.20-24). Madrid. - Ayarzagüena Sanz, M. (2013). El marco político, económico, social y cultural de España (1939-1975). En M.I. Porras-Gallo, et al (Coords.), El drama de la polio. Un problema social y familiar en la España franquista, (pp. 32-47). Madrid: Los libros de la Catarata,

- Báguena Cervellera, Mª.J. (2004). Saberes y prácticas en torno a la polio en la medicina valenciana (1900-1950). En J. Martínez Pérez, et al (Coords.), La medicina ante el nuevo milenio: una perspectiva histórica, (pp.949-962). Cuenca: Editorial de la Universidad de Castilla-La Mancha.

- Báguena Cervellera, Ma .J. (2009). Estudios epidemio- 
lógicos y virológicos sobre la poliomielitis en Valencia (1959-1969). Asclepio. Revista de Historia de la Medicina $y$ de la Ciencia, 1, 39-54.

- Ballester, R. y Porras, M.I. (2009). El significado histórico de las encuestas de seroprevalencia como tecnología de laboratorio aplicada a las campañas de inmunización. El caso de la poliomielitis en España. Asclepio. Revista de Historia de la Medicina y de la Ciencia, 1, 55-80.

- Ballester, R. y Porras, Ma.I. (2012). La lucha europea contra la presencia epidémica de la poliomielitis: una reflexión histórica. Dynamis, 2, 273-285.

- Cabral Chamorro, A. (1990). Una aproximación a la crisis de la vid y del vino en el marco de Jerez: el caso de Trebujena. Agricultura y Sociedad, 57, 241-260.

- Capel Sáez, H. (1971). La Red urbana española: 19501960. Tesis doctoral. Departamento de Geografía. Barcelona: Universidad de Barcelona. Disponible en: ¡Error!Referencia de hipervínculo no válida. (Consultado el 26 de julio de 2015).

- Caro Cancela, D. (1999). Jerez Contemporáneo (siglos XIX y XX). En D. Caro Cancela (Coord.), El Jerez moderno y contemporáneo (pp.195-438). Cádiz: Servicio de Publicaciones de la Diputación Provincial de Cádiz.

- Celebración del 50 aniversario de la instauración de la campaña de vacunación antipoliomielitis en España. Homenaje al Dr. D. Florencio Pérez Gallardo (2013). Revista Española de Salud Pública, 87,5. Disponible en http://scielo.isciii.es/scielo.php?script=sci_ issuetoc\&pid $=1135-572720130005 \& \operatorname{lng}=$ pt\&nrm $=$ iso (Consultado el 8 de agosto de 2015).

- Cruz-Hernández, M. (1959). Consideraciones sobre las formas graves de poliomielitis en el último brote epidémico de Cádiz. Farmaes, 57-73.

- Cruz-Hernández, M. (1972). Pediatría y Puericultura. Barcelona: Editorial Romargraf.

- Domingo Fernández, C.J. y Contreras Carrasco, G. (2006). Los tiempos del piloto. Anales de la Real Academia Nacional de Medicina, CXXIII, 4, 747-757.

- Fernández-Cruz, E., Rodríguez-Sáinz, C. (2013). Inmunología de la poliomielitis: vacunas, problemas para la prevención/erradicación e intervenciones de futuro. Revista Española de Salud Pública, 87, 443-454
- Ferrán Martínez Navarro, J. (2013). Los estudios epidemiológicos sobre la poliomielitis en España antes de la vacunación. Revista Española de Salud Pública, 5, 429441.

- Fundación Juan March. Ayudas de investigación (19571962). Disponible en: http://recursos.march.es/web/ prensa/anales/1956-1962/8-Ayudas-de-investigacion. pdf (Consultado el 26 de julio de 2015).

- González Rodríguez, P. (1953). Aspectos epidemiológico y social de la poliomielitis. La parálisis infantil en España (folleto para médicos). Madrid: Dirección General de Sanidad.

- Herrera-Rodríguez, F. (1990). Enrique Alcina Quesada (1879-1943) y su visión de la enfermera durante la Guerra Civil española. En Libro de Actas del Primer Encuentro Interdisciplinar de Estudios de la Mujer (tomo I, 433-441), Granada.

- Herrera-Rodríguez, F. (2006). Antonio Orozco Acuaviva: un médico humanista en la Academia Hispanoamericana. Cádiz: Real Academia Hispanoamericana de Ciencias, Artes y Letras de Cádiz..

- Herrera-Rodríguez, F. (2007). La obra sanitaria de Leonardo Rodrigo Lavín (1867-1950). Cádiz: Fundación Provincial de Cultura (Diputación de Cádiz).

- Herrera-Rodríguez, F. (2011). Un viaje a Newark en busca de la polio. Cultura de los Cuidados, 31, 30-40.

- Herrera-Rodríguez, F. (2012) Polio y Rehabilitación en la obra de Antonio Orozco Acuaviva. Llull, 76, 339-340.

- Herrera-Rodríguez, F. (2015). Una revisión de Pedro Rodrigo Sabalette sobre la poliomielitis (1948). Cultura de los Cuidados, 41, 56-70.

- León Rega, P., Echevarría Mayo, J.M. (2005). La poliomielitis y el síndrome post-polio; una breve revisión. Disponible en http://www.postpoliomexico.org/PolioPostPolioBreveResumen.html (Consultado el 26 de julio de 2015). - Martínez-Perez, J. (2009a). Presentación: La poliomielitis como modelo para el estudio de la enfermedad en perspectiva histórica. Asclepio. Revista de Historia de la Medicina y de la Ciencia, 1, 7-21.

- Martínez-Pérez, J. (2009b). Consolidando el modelo médico de discapacidad: sobre la poliomielitis y la constitución de la traumatología y ortopedia como especialidad 
en España (1930-1950). Asclepio. Revista de Historia de la Medicina y de la Ciencia, 1, 117-142.

- Muñoz Singi, G. (2007). La poliomielitis en la prensa salmantina (1954-1967. Tesis doctoral dirigida por el Dr. Juan A. Rodríguez Sánchez. Salamanca: Universidad de Salamanca.

- Nájera, E. y otros (1975). Análisis epidemiológico de la situación actual de la poliomielitis en España. Revista de Sanidad e Higiene Pública, 49, 953-1.025.

- Nájera, R. (2006a). Florencio Pérez Gallardo (19172006). Revista Española de Salud Pública, 80, 605-608.

- Nájera, R. (2006b). Recuerdos de una vida. Anales de la Real Academia Nacional de Medicina, CXXIII, 4, 759776.

- Nájera, R. (2013a). La eliminación de la Poliomielitis en España. Virología, 3, 33-37. Disponible en: http:// sevirologia.es/media/uploads/ultimo_numero_revista_ sev/06historia.pdf (Consultado el 3 de agosto de 2015).

- Nájera, R. (2013b). Hilary Koprowski (1916-2013). Virología, 3, 33-37. Disponible en: http://sevirologia.es/ media/uploads/ultimo_numero_revista_sev/06historia. pdf (Consultado el 3 de agosto de 2015).

- Pachón del Amo, I. (2004). Historia del programa de vacunación en España. En C. Amela, (Coord.), Epidemiología de las enfermedades incluidas en un programa de vacunación (pp.9-16). Madrid: Sociedad Española de Epidemiología y Emisa.

- Pérez Gallardo, F., Valenciano Clavel, L., Gabriel y Galán, J. (2013). Resultados de la campaña Nacional de Vacunación Antipoliomelítica por vía oral en España (Estudio virológico y epidemiológico). Revista Española de Salud Pública, 87, 523-540.

- Porras-Gallo, M.I., Báguena, M.J., Ballester, R., De las Heras, J. (2012). La Asociación Europea contra la Poliomielitis y los programas europeos de vacunación. Dynamis, 32, 287-310.

- Porras-Gallo, M.I., Ayarzagüena Sanz, M., Heras Sarlord de las, J., Báguena Cervellera, Ma J. (coords.) (2013). El drama de la polio. Un problema social y familia en la España franquista. Madrid: Los Libros de la Catarata.

- Porras-Gallo, M.I. (2014) La poliomielitis en la España franquista: educar e reeducar. Educar em Revista Curi- tiva, 54, 71-95.

- Reseña Estadística de la provincia de Cádiz (1957). Presidencia del Gobierno. INE, Madrid.

- Rey Calero, J. Florencio Pérez Gallardo in memoriam. Anales de la Real Academia Nacional de Medicina, CXXIII, 4,739-746.

- Rodríguez-Sánchez, J.A. y Seco-Calvo, J. (2009). Las campañas de vacunación contra la poliomielitis en España en 1963. Asclepio. Revista de Historia de la Medicina y de la Ciencia, 1: 81-116.

- Rodríguez-Sánchez, J.A. (2010). Responsabilidades nao assumidas: a poliomielite na Espanha (1954-1967). En D. Raimundo do Nascimento (coord.), A história da poliomielite. Garamondn (pp.195-224). Río de Janeiro.

- Rodríguez-Sánchez, J.A. (2012). Las secuelas sociales de la polio: el inicio del movimiento asociativo en España (1957-1975). Dynamis, 2, 391-414.

- Rodríguez-Sánchez, J.A. (2013). Poliomielitis y movimiento antivacunacionista en España (1955-1963). En Actas I Congreso de Historia Contemporánea, IHC (pp.145-159). Lisboa-Coimbra.

- Rodríguez-Sánchez, J.A. (2013b). Del control a la erradicación: salud pública y atención primaria en la lucha contra la polio en España (1963-1988). Ponencia presentada en Seminario Política, Salud y Enfermedad en España: entre el desarrollismo y la transición. Alicante: Museo Arqueológico Provincial de Alicante, 12-13 de diciembre.

- Rodríguez-Sánchez, J.A. (2014). De las campañas de vacunación al calendario vacunal: el Programa Nacional de Vacinaçao portugués y las Campañas Nacionales de Vacunación Antipoliomielítica en España (1963-1967). En R. Campos Marín et al. (Coords.), Medicina y Poder Político. Sociedad Española de Historia de la Medicina (pp.203-210). Madrid: Universidad Complutense.

- Rodríguez-Sánchez, J.A. (2015). An Introduccion (Guest Editor). En Poliomyelitis after Poliomyelitis: Light and shadow of the erradication. Higyiea Internationalis an interdiscinary Journal for the history of Public Health, 1, 7-31.

- Ruiz Mata, J. (2010). Breve Historia de Jerez de la Frontera. Tierra de Nadie Editores, Jerez de la Frontera. 


\section{ᄃultura de las Cuidados}

- Sáinz-Otero, A. (2007). La mortalidad en Cádiz (19231939). Tesis doctoral. Cádiz: Facultad de Medicina Universidad de Cádiz.

- Tuells, J. (2008). Los testimonios de los expertos y su participación en las primeras campañas de vacunación an- tipoliomielíticas en España. En: T. Ortiz et al (Coords.), La experiencia de enfermar en perspectiva histórica (pp.321-324). Granada: Universidad de Granada.

- Tuells, J. (2010). El frágil inicio de la cadena de frío vacunal en España. Gaceta Sanitaria, 24, 354-357.

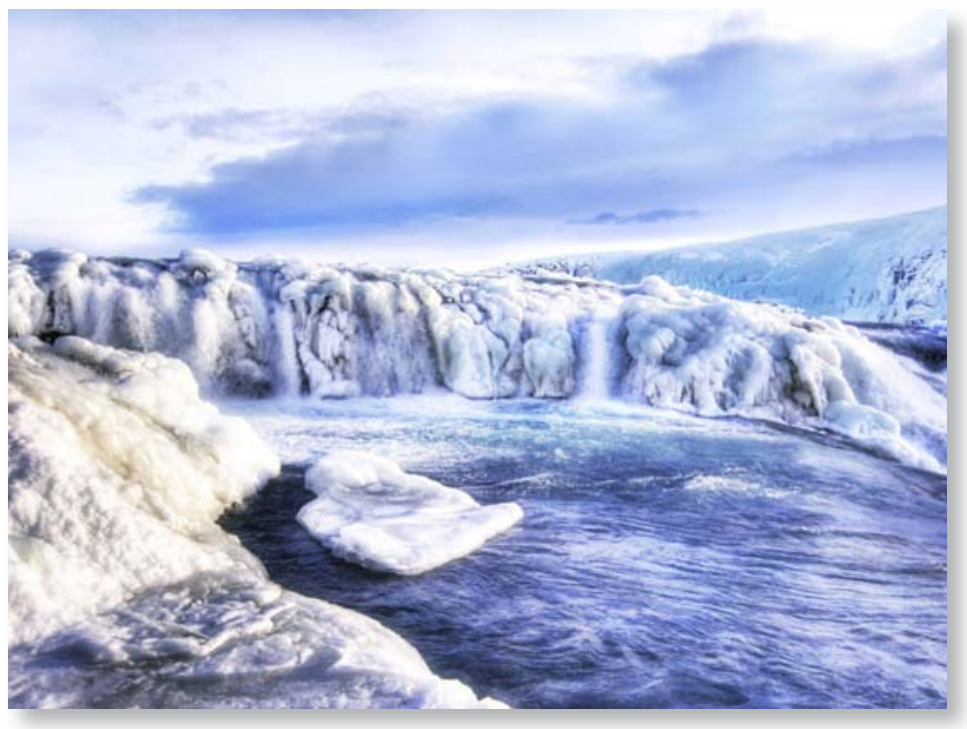

